\title{
LA POSIBLE IGLESIA RURAL ALTOMEDIEVAL DE LA SOLANA I (MÓSTOLES, MADRID). EL CARÁCTER CENTRAL DE SU EMPLAZAMIENTO Y SUS VÍNCULOS CON EL POBLAMIENTO ALDEANO
}

\author{
THE POSSIBLE EARLY MEDIEVAL CHURCH IN LA SOLANA I (MÓSTOLES, MADRID). \\ ITS CENTRAL LOCATION AND LINKS TO THE VILLAGE SETTLEMENT
}

JESÚS RODRÍGUEZ MORALES

I.E.S. Juan Gris, Móstoles

Universidad Antonio de Nebrija

ALFONSO VIGIL-ESCALERA GUIRADO

Universidad del País Vasco/Euskal Herriko Unibertsitatea

ALEJANDRO VILLA DEL CASTILLO

Consejo Superior de Investigaciones Científicas

\section{INTRODUCCIÓN}

La intensa investigación arqueológica llevada a cabo sobre las iglesias altomedievales ibéricas durante el último cuarto de siglo ha pivotado, como es lógico, sobre un corpus de edificios total o parcialmente conservados (Utrero, 2006, 2010; Sánchez Zufiaurre, 2007; Caballero, 2011, 2013; Quirós 2011; Sánchez-Pardo 2012). En este trabajo se presentan y analizan las evidencias disponibles acerca de un yacimiento arqueológico no excavado, y del que tampoco se conservan estructuras visibles en superficie. Diversas piezas de escultura decorativa, recuperadas a través de prospecciones y hallazgos esporádicos, avalan la presencia de uno de los escasos ejemplos de arquitectura altomedieval de prestigio de la región madrileña.

En primer lugar se analizarán los testimonios materiales proporcionados por el yacimiento arqueológico de La Solana I y su inserción en el contexto altomedieval regional. A continuación se llevará a cabo un estudio pormenorizado de los elementos arquitectónicos recuperados, valorando sus vínculos con los de otros yacimientos coetáneos peninsulares. En tercer lugar se recopilarán y valorarán de forma crítica las menciones referentes al antiguo poblamiento de esta zona y sus edificios de culto en las fuentes escritas. Para terminar se discutirá el significado del conjunto de evidencias de cara a la interpretación histórica $\mathrm{y}$ funcional del edificio y del yacimiento. Merecerán una especial atención sus nexos con el poblamiento rural altomedieval del entorno y la de éste con la trama de aldeas que desde los siglos XII-XIII aparece configurada en la documentación escrita. La reflexión sobre el yacimiento y su contexto da lugar al esbozo de dos líneas de investigación de cara al futuro. La primera concierne al significado del emplazamiento de las iglesias rurales en el ámbito de la gestión territorial por parte de las comunidades aldeanas, al carácter central que posiblemente desempeñaron estos lugares en el universo campesino. La segunda atañe a las posibles líneas de continuidad existentes entre el paisaje rural alto y plenomedieval. Profundizar en el estudio de esta cuestión tal vez permita comprender mejor lo que hay tras el proceso de repoblación de estos territorios de la Meseta Sur.

El interés que suscita el yacimiento de La Solana I se justifica por diversas razones. La primera deriva de la singularidad del mismo en el contexto regional, extremadamente rico en evidencias arqueológicas de modesta entidad para el periodo visigodo, pero carente de producciones arquitectónicas monumentales o de cierta complejidad conservadas ${ }^{1}$. Como se verá a continuación, el sitio aporta los primeros hallazgos de escultura decorativa del grupo toledano de Guadamur-Sonseca-Orgaz al Norte del río Tajo, ampliando el ámbito en el que parece desenvolverse este taller o

\footnotetext{
1. Al margen de ciertos indicios en las ciudades de Madrid y Talamanca, seis sitios en la actual Comunidad de Madrid han librado hasta la fecha testimonios materiales acerca de posibles iglesias rurales de origen altomedieval: El Berrueco, Villaviciosa de Odón, Boadilla del Monte, Valdeolmos, Griñón y el sexto sería el que se aborda en el presente trabajo (Vigil-Escalera, e.p.).
} 
conjunto de constructores. Proporciona además información sensible de la hasta ahora desconocida relación mantenida entre los asentamientos campesinos de época visigoda y los edificios de culto que pudieron ser coetáneos. Contribuye, por último, a desvelar posibles pautas de explotación del territorio (la pervivencia de determinados usos del suelo) y el funcionamiento de prácticas sociales intercomunitarias en el intervalo que media entre el periodo visigodo y la reestructuración del poblamiento rural de los siglos XII-XIII d.C. en el distrito toledano.

A diferencia de lo que ocurre con los valles colindantes en la margen oriental del río Guadarrama, no consta la existencia en el del arroyo de El Soto de un asentamiento aldeano extenso y con ocupación plurisecular de época visigoda ${ }^{2}$. Sin embargo, tanto la propia materialidad del edificio que se levantó en La Solana I como la documentación textual de época posterior convergen en un punto: la importancia que desempeñó este tramo del arroyo de El Soto para el conjunto de comunidades aldeanas de su entorno durante un periodo plurisecular. Se discutirá luego la posibilidad de que la elección del emplazamiento del edificio pueda vincularse al hecho de que el lugar ya desempeñaba desde antes ese carácter nuclear, aunque tampoco puede descartarse la alternativa: que esa centralidad fuera reivindicada a partir de la inversión volcada por unos promotores desconocidos en esa construcción. En todo caso, cualquier atisbo de continuidad o pervivencia de usos que pueda aducirse entre el periodo visigodo y el que se conforma a partir de los siglos XII-XIII no puede valorarse de forma adecuada sin exponer antes las particulares circunstancias históricas que atraviesa esta región del interior peninsular entre los primeros siglos altomedievales y el momento en el que hace su aparición este distrito en las fuentes documentales.

La imagen que ofrece el poblamiento rural en las comarcas del Sur de Madrid entre los siglos V y VIII d.C. ha sido desarrollada en varios trabajos recientes (Vigil-Escalera, 2007; Vigil-Escalera y Quirós, 2013). Numerosos asentamientos campesinos han podido identificarse merced a intervenciones arqueológicas de urgencia vinculadas sobre todo a proyectos de desarrollo urbanístico. La distribución de distintos tipos de materiales a lo largo del territorio (especialmente cerámica y molinos manuales) demuestra un elevado nivel de integración socioeconómica a escala regional. La asociación de asentamientos y cementerios dota a estas primeras aldeas de una sustancial estabilidad. De su distribución espacial se infiere que dispusieron de contornos territoriales precisos. La gestión del espacio funerario revela la existencia de pautas que refuerzan

2. Se conocen asentamientos ocupados entre los siglos V y VIII d.C. tanto inmediatamente al Sur (El Pelícano) como al Norte (Monte la Villa-Yac. 3N) (Vigil-Escalera, 2013b, 179-180, fig. 2.100). la cohesión comunitaria y dotan de una identidad específica a sus miembros (Vigil-Escalera, 2013a).

La conquista islámica en 711 no supuso una quiebra inmediata de la estructura del poblamiento rural de época visigoda, estimándose que muchas aldeas continuaron activas hasta mediados del siglo VIII d.C. Los cien años siguientes parecen conformar un periodo de intensas transformaciones. Entre mediados del siglo VIII y mediados del IX se abandonan todos los asentamientos rurales conocidos hasta la fecha. La mayor parte de la población debió concentrarse en los suburbios de determinados centros protourbanos y a la sombra de las numerosas fortalezas distribuidas por el territorio. Muchas comunidades se convirtieron al Islam en un corto espacio de tiempo, como revelan algunos sitios a orillas del río Jarama (Vigil-Escalera, 2009). A la conversión religiosa siguieron, con sus propios ritmos, cambios en las costumbres, la organización familiar y la del espacio doméstico o las formas de explotación económica del territorio, aunque la información directa es aún muy parca al respecto. Las primeras noticias sobre las ciudades de Madrid o Talamanca se remontan al gobierno del emir cordobés Muhammad I (852-886), mientras que Calatalifa, la principal fortaleza y centro político en la cuenca media del río Guadarrama, no resulta citada hasta la primera mitad del X (Retuerce, 2004; Rodríguez Morales, 2007). La inestabilidad política y militar de la Marca Media no se debió solo a su condición fronteriza sino a la resistencia mostrada por la oligarquía de Toledo a las tendencias centralizadoras del estado cordobés (Manzano, 2006, 318-29). Las numerosas intervenciones arqueológicas desarrolladas en los cascos históricos de Madrid o Toledo durante los últimos treinta años se han mostrado incapaces de aportar información relevante sobre lo sucedido entre el siglo IX y el XII d.C. La presión de los reinos cristianos del Norte desembocó en la conquista de Toledo y su distrito en 1085. Sin embargo, la frontera no se retiraría definitivamente hacia el Sur peninsular hasta un siglo más tarde.

Un puñado de evidencias es todo lo que hay disponible para rellenar el vacío existente en el conocimiento del poblamiento rural entre los siglos IX y XII. Solamente a partir del siglo XII, y especialmente de su segunda mitad, la evidencia arqueológica proporciona testimonios de una nueva ocupación del medio rural por comunidades campesinas. La frecuencia con la que el espacio residencial de estas aldeas coincide con la de despoblados altomedievales es bastante llamativa (Vigil-Escalera y Quirós, 2013, 397).

\section{EL YACIMIENTO ARQUEOLÓGICO DE LA SOLANA I (MÓSTOLES)}

El yacimiento denominado La Solana I ( $n^{\circ}$ inv. 0092/028) fue catalogado a raíz de la revisión de la Carta Arqueológica del término de Móstoles llevada a cabo en 2005, aunque tres años antes ya se habían 


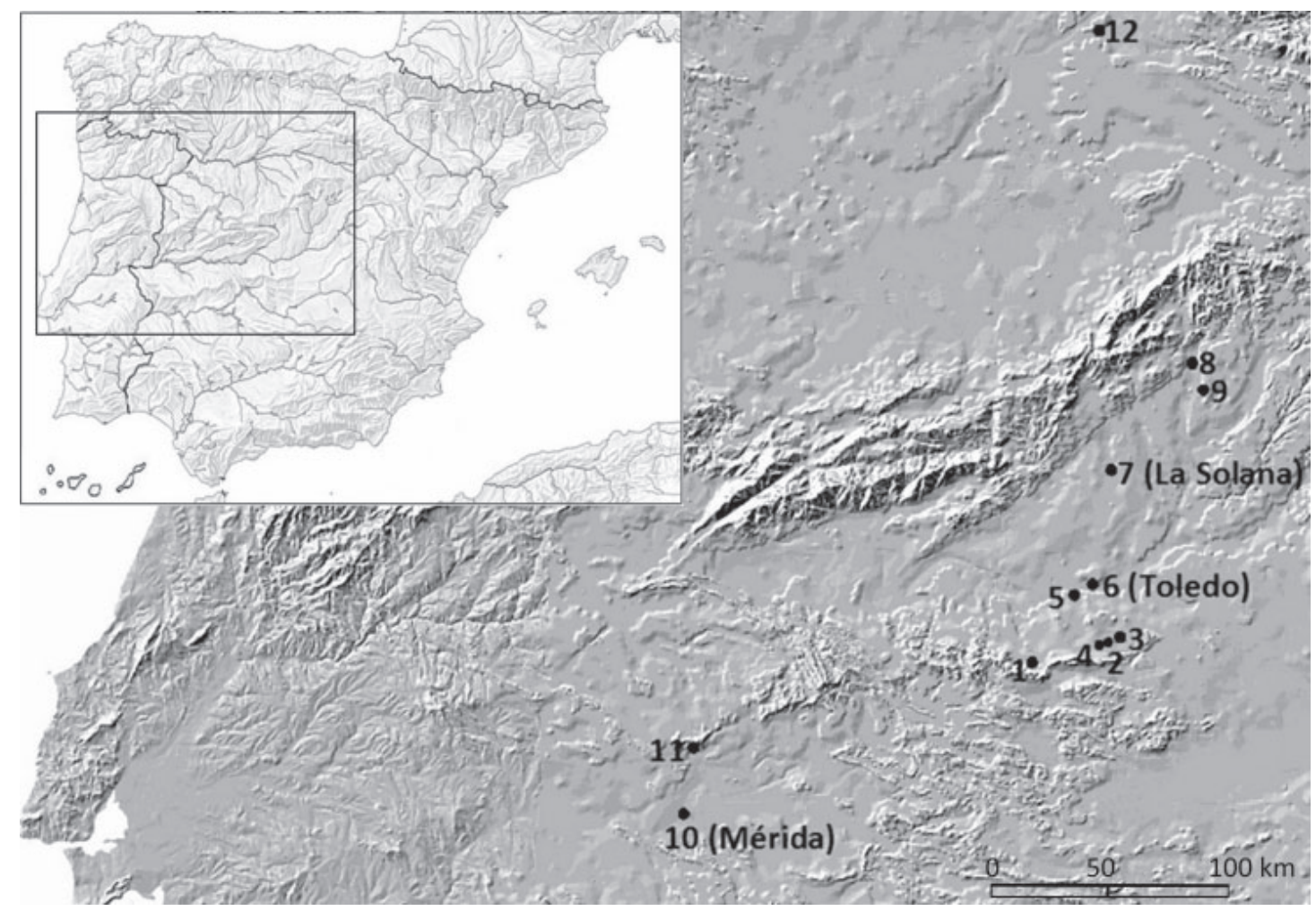

Figura 1: Mapa del interior peninsular con la localización de los principales sitios citados en el texto: 1. San Pablo de los Montes; 2. Los Hitos (Arisgotas, Orgaz); 3. Orgaz; 4. San Pedro de la Mata (Casalgordo, Sonseca); 5. Guarrazar (Guadamur); 6. Toledo; 7. La Solana I (Móstoles); 8. Talamanca del Jarama; 9. Valdeolmos; 10. Mérida (Badajoz); 11. Santa Lucía del Trampal (Alcuéscar, Cáceres); 12. Granja de Retortillo (Burgos).

publicado algunos materiales procedentes del sitio, efectuándose la identificación de sus restos con los de una iglesia de época visigoda (Rodríguez y García, 2002, 58-62). Se recopilaba además la información existente sobre los hallazgos producidos en las inmediaciones a lo largo de los años (Viloria, 1955, 40).

El sitio presenta unas precarias condiciones de conservación desde el punto de vista patrimonial. Las labores agrícolas han ido sacando a la superficie durante años distintos materiales cuya descripción y análisis se abordará a continuación ${ }^{3}$. Su preservación sigue estando comprometida en la actualidad. Sería deseable que un mejor conocimiento del mismo suscitase la adopción de las medidas de protección, difusión y aprovechamiento público que el sitio demanda con urgencia.

El yacimiento se localiza en el extremo occidental del término de Móstoles, a unos $22 \mathrm{~km}$ al Suroeste de la capital, Madrid (Fig. 1). La parte septentrional de la comarca de La Sagra madrileña se caracteriza por un relieve de campiña de suaves lomas surcadas por arroyos. El sustrato geológico lo forman arcosas

3. Parte de ese material se ha depositado en el Museo Arqueológico Regional de la Comunidad de Madrid. Comprende diversos elementos arquitectónicos de pequeño tamaño, cerámica doméstica y otros materiales diversos. Se agradece a los responsables del Museo su colaboración, en especial a su director E. Baquedano, y al personal del mismo: Antonio Dávila y Miguel Contreras. feldespáticas y otros materiales detríticos (en general, arenas gruesas). Los suelos son ligeros y poco profundos, muy vulnerables a la erosión, aptos para cultivos poco exigentes como los del cereal de secano. El sitio ocupa una posición a media ladera, en la orilla Norte del arroyo de El Soto, tributario por la margen izquierda del río Guadarrama. El arroyo ha sufrido durante los dos últimos milenios un progresivo encajonamiento. El descenso de cota de su lecho se aprecia por ejemplo a la altura de una presa de época medieval o moderna ${ }^{4}$, con su fábrica de ladrillo y mortero colgando actualmente a más de dos metros sobre el cauce.

El perímetro administrativo del yacimiento (al Este y Sur de un bloque de parcelas urbanizadas) alberga testimonios de distintos periodos. En el extremo Suroeste, ladera abajo, es posible reconocer aún restos de construcciones de época romana con materiales asociados que cubren los dos o tres primeros siglos de la Era. En los escarpes de la margen Norte del arroyo se entrevén tramos de muros con fábrica de mortero de cal y un pie de anchura, similares a los documentados a menos de cinco kilómetros al Sur, en el establecimiento romano de El Pelícano (Arroyomolinos). La

4. Tal vez del siglo XVI, presenta similitudes con los sistemas hidráulicos documentados en otros arroyos del entorno, como el de Los Combos, en Arroyomolinos. Se desconoce si sirvió a un molino de cubo, o la localización exacta de éste. 


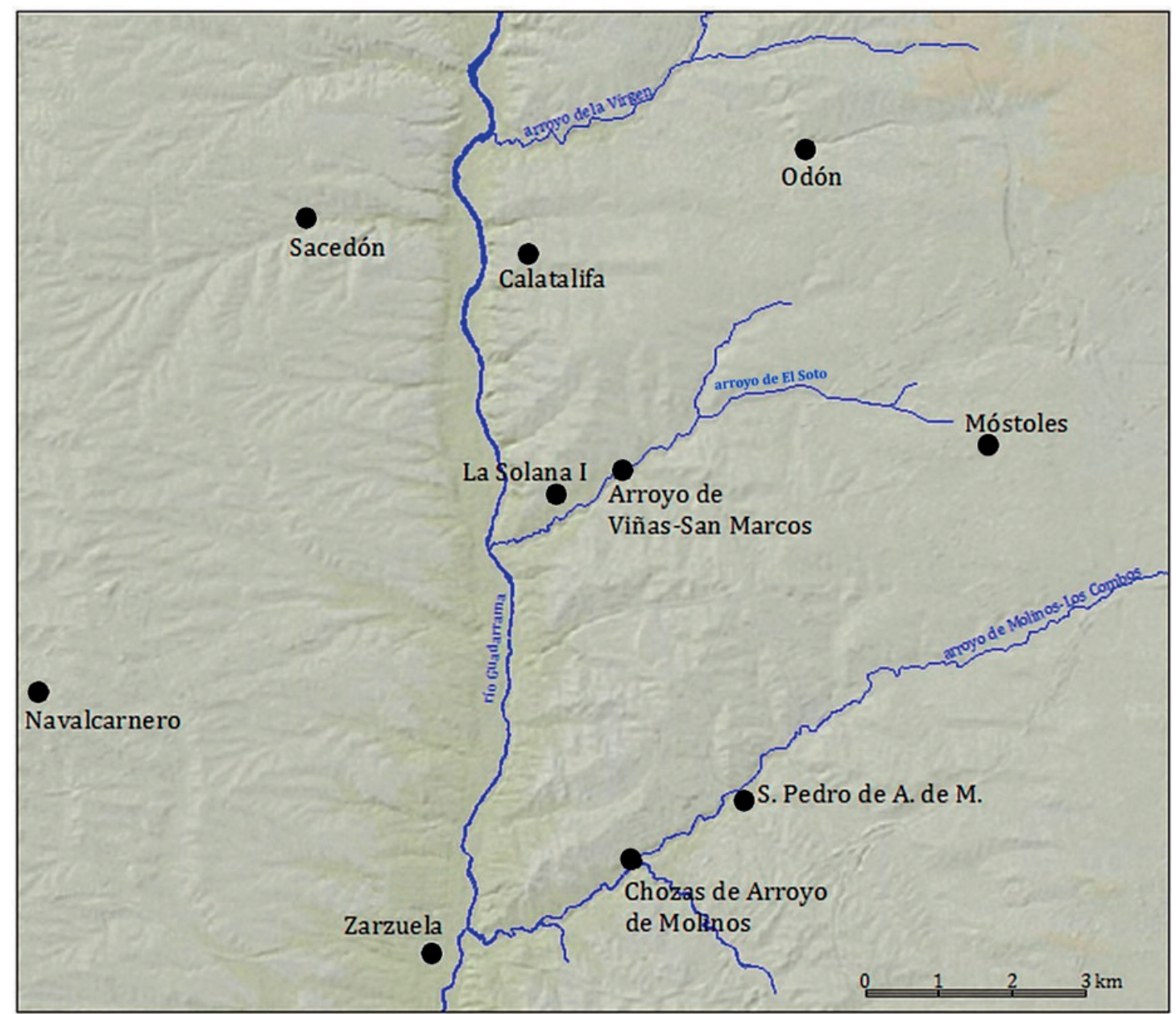

Figura 2: Situación de La Solana I y Arroyo de Viñas-San Marcos y de algunas de las localidades limítrofes citadas en el texto.

estela romana recuperada en el año 2002 podría haber pertenecido al espacio funerario asociado a este asentamiento o haber sido trasladada para usarse en la fábrica del edificio altomedieval que nos ocupa (Rodríguez Morales, 2011, 156).

El valle del arroyo de El Soto alberga una apreciable cantidad de yacimientos de todos los periodos. A causa de la relación con el que aquí nos ocupa debe destacarse el denominado San Marcos (0092/030), localizado aproximadamente un kilómetro aguas arriba del de La Solana (Fig. 2). Los materiales de superficie podrían asociarse al despoblado de la aldea de Arroyo de Viñas o uno de sus barrios (siglos XIII-XIV), aunque se han identificado también cerámicas asignables a frecuentaciones más antiguas (desde época romana) y modernas.

Los restos materiales visibles en superficie de La Solana I se extienden por unos $10.200 \mathrm{~m}^{2}$, dentro de un perímetro de unas tres hectáreas y media. Se trata de una superficie bastante modesta si se la compara con las de la mayor parte de los asentamientos de época visigoda conocidos en las campiñas madrileñas (VigilEscalera y Quirós, 2013, 358-59, Tabla 7.1). El sitio ocupa la parte media de una ladera de suave pendiente orientada a Sur, con caída hacia el arroyo de El Soto, que desemboca por el Oeste en el río Guadarrama. Sobre el parcelario actual, el yacimiento ocupa las parcelas catastrales numeradas 106 a 115 del polígono 26. Sería posible distinguir distintos ámbitos en función del tipo de evidencias (Fig. 3).

Por un lado se encuentra la parcela 111, no cultivada, algo elevada respecto a sus colindantes por el Sur y el Oeste. Marca un escalón de aproximadamente un metro en su esquina Suroeste que va difuminándose en dirección Norte y Este. Su configuración invita a pensar que ha permanecido inculta debido a la presencia de construcciones de cierta solidez en su subsuelo 5 .

La mayor parte del material arqueológico se concentra al Sur y al Sudeste de la parcela citada. Se puede observar una concentración de teja curva bastante fragmentada junto con cerámica doméstica, restos óseos de fauna y algunos cantos rodados de cuarzo. La coloración del terreno, más oscura que en su entorno, señala la probable existencia de fosas rellenas con desechos domésticos con una apreciable cantidad de materia orgánica

5. Las series históricas de fotografía aérea disponibles prueban que durante el último medio siglo no ha sido cultivada con regularidad. 


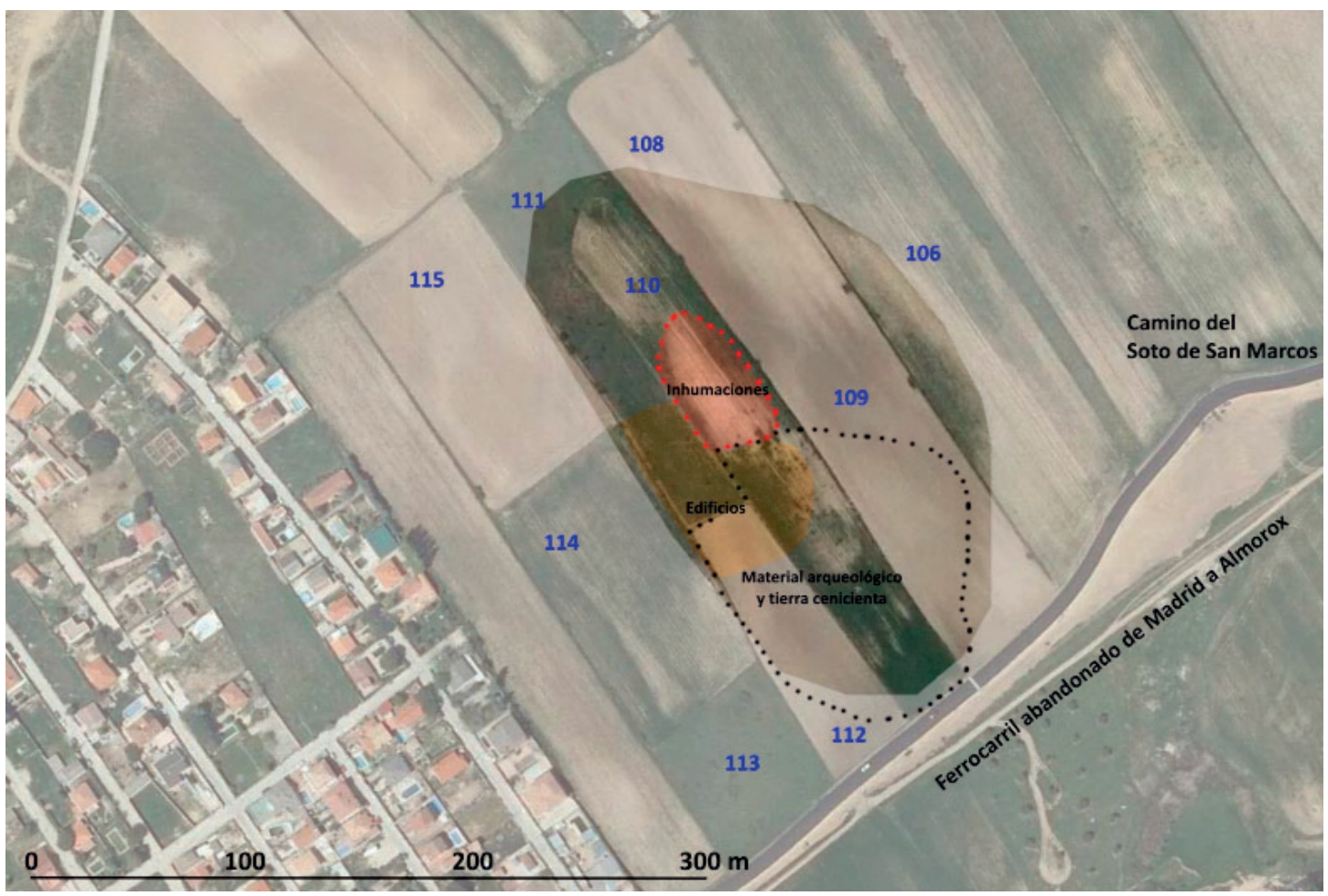

Figura 3: Distribución de los hallazgos de La Solana I, con indicación del número de las parcelas.

(cenizas). El material ha sido intensamente removido por las labores agrícolas y tiende a dispersarse ladera abajo. El arado ha alcanzado mayor profundidad en algunos puntos donde el terreno ofrece menos resistencia, denotando la presencia de fosas colmatadas con rellenos poco compactos. Al Norte, las últimas labores han incidido sobre los restos ocultos de alguna estructura con fábrica de mortero de cal y ladrillos planos, dejando restos de ambos materiales a lo largo de los surcos. En esta zona también han podido reconocerse restos óseos humanos, procedentes del probable desmantelamiento de un número indeterminado de inhumaciones.

Los materiales cerámicos reconocibles en superficie indican que el yacimiento estuvo ocupado al menos durante el siglo VIII d.C. La mayor parte es atribuible a producciones comunes de época tardovisigoda (no torneadas, tipo TL2) características de la región de Madrid $^{6}$ (Vigil-Escalera, 2003). Un porcentaje pequeño pero significativo de la cerámica (aproximadamente un 5\%) corresponde a cuencos o jarritas de pastas depuradas de color ocre-anaranjado. En uno de ellos se reconoce decoración pintada de pequeños trazos rojizos (Fig. 4). La aparición conjunta de estas dos clases de producciones se encuentra bien constatada en otros contextos del interior peninsular datados a lo largo de la segunda mitad de la octava centuria (VigilEscalera, 2011). A caballo entre los siglos VIII y IX

6. Cerámicas de este tipo se encuentran ausentes, por ejemplo, en los niveles fundacionales de Alcalá la Vieja (López Marcos et alii, 2013).
d.C. tuvo lugar la irrupción de cerámicas torneadas (ollas especialmente) cuya presencia no ha sido posible reconocer entre el material de prospección. Resulta difícil de determinar el posible momento de inicio de la ocupación, ya que las producciones no torneadas evolucionan sin demasiados cambios entre los siglos VII y VIII d.C. La ausencia de los tipos cerámicos regionales característicos del siglo VI d.C. constituye igualmente un dato a tener en consideración.

Se tiene noticia del hallazgo en el yacimiento de un triente acuñado durante el reinado de Egica (Rodríguez Morales, 2005, 94). Las implicaciones de la presencia de moneda visigoda en yacimientos rurales de este periodo han sido destacadas en algunos trabajos recientes (Martín Viso, 2008, 2011), ligándose en

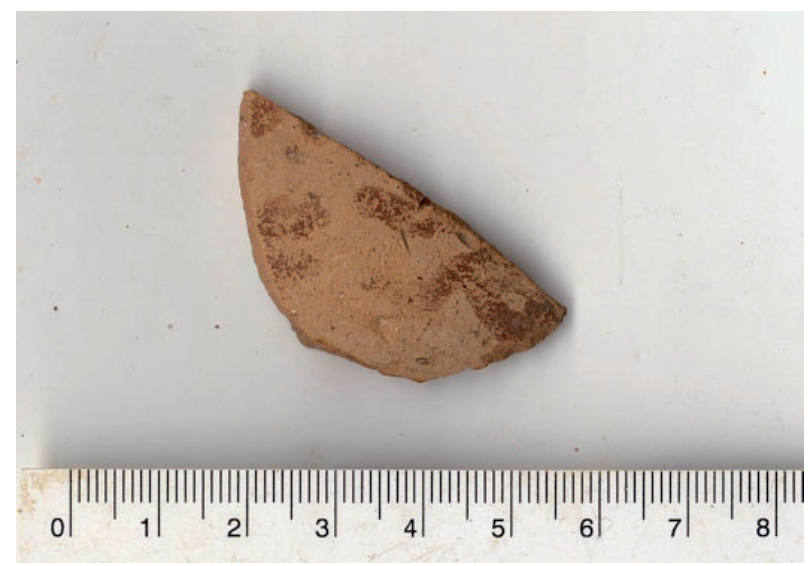

Figura 4: Fragmento de un jarrito con restos de decoración pintada en rojo. 
ciertos casos a la presencia de potentes o aristocracias rurales, unidas al regnum a través de su intervención en la gestión y organización de la recogida de tributos. Materiales arqueológicos más modestos pero indicativos del desarrollo de actividades domésticas son algunos fragmentos de molinos rotatorios manuales de granito. De prospecciones previas en estas parcelas se custodia en el Museo Arqueológico Regional una caja con ladrillos planos con profundas digitaciones.

Tanto en las lindes de las parcelas como a lo largo de las mismas (en menor densidad) han aparecido mampuestos de caliza incluso de considerable tamaño, a menudo con alguna cara desbastada. Este material contrasta de manera llamativa con los habituales cantos rodados que forman el repertorio pétreo básico de la arquitectura doméstica en toda la comarca. La presencia de decoración en el material constructivo citado o la de elementos con funciones específicas dentro de una arquitectura de prestigio sugiere que en el yacimiento se alzó una construcción inhabitual en el panorama de las aldeas altomedievales de la región ${ }^{7}$. Las características de estos materiales se verán en el siguiente apartado.

\section{ANÁLISIS DE LOS ELEMENTOS ARQUI- TECTÓNICOS RECUPERADOS EN EL SITIO}

En el presente epígrafe se abordará el estudio de los elementos de escultura decorativa recuperados en el yacimiento de La Solana I. En primer lugar analizaremos los materiales de forma individualizada atendiendo a su funcionalidad, soporte, decoración y dimensiones, poniendo en relación cada uno de ellos con piezas escultóricas ya conocidas. Posteriormente intentaremos contextualizarlos en el ámbito de la escultura altomedieval toledana e hispana, para finalmente proponer una serie de hipótesis interpretativas y cronológicas.

El conjunto lapídeo analizado procede de prospecciones y recogidas de superficie. Existe pues un límite claro que atañe al estudio e interpretación del conjunto: la ausencia de un contexto arqueológico o arquitectónico cerrado. Las conclusiones del trabajo han de tener, por tanto, un carácter provisional.

\section{III.1. Piezas RECUPeradas EN LA Solana I (Móstoles) $^{8}$}

1. MAR DSZ5793 2009-14-01. Pieza de friso o imposta de bóveda decorada con un roleo vegetal con

7. El carácter esporádico del material de fábrica visible en superficie impide abordar un análisis de las técnicas constructivas en el sentido propuesto por Quirós y Fernández Mier (2012, 40-42).

8. Gran parte del material fue recogido por D. José Martín Roldán. Las piezas se hallan depositadas en el Museo Arqueológico Regional de Alcalá de Henares. Piezas 1-7 ( $\mathrm{N}^{\circ}$. Exp.

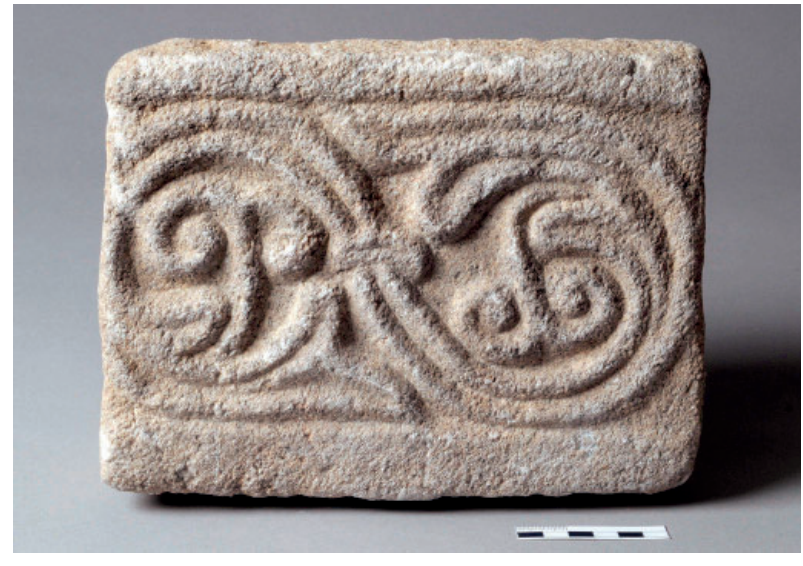

Figura 5: Fragmento de friso o imposta recortado por su lado izquierdo (Museo Arqueológico Regional).

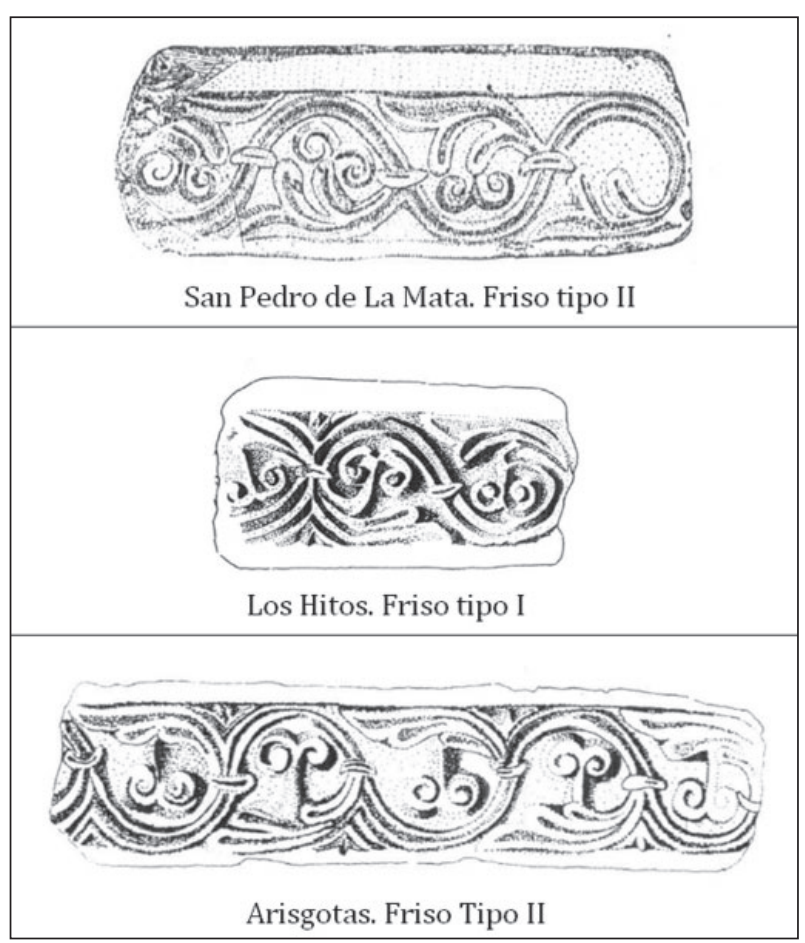

Figura 6: Algunos paralelos conocidos de la pieza anterior (según Balmaseda, 1998).

anilla y de cuyas hojas nacen dos estilizaciones de zarcillos de vid (Fig. 5) ${ }^{9}$. El motivo se completa con dos filetes que sirven de marco a la composición. El soporte es una caliza marmórea de grano grueso ${ }^{10}$. La pieza

9/14, Cajas 1 y 2); pieza 8 (hallazgo casual, Móstoles, №. Exp. 05/112, Caja 1, Arroyo de los Combos y Arroyo del Soto).

9. Las piezas 1, 3, 6 y 8, así como un pequeño fragmento decorado y actualmente perdido, fueron dados a conocer en un trabajo dedicado al Móstoles romano (Rodríguez y García, 2002, 59).

10. Este material se emplea en gran parte de la escultura decorativa procedente de los edificios de San Pedro de La Mata (Casalgordo, Sonseca, Toledo) y Los Hitos (Arisgotas, 

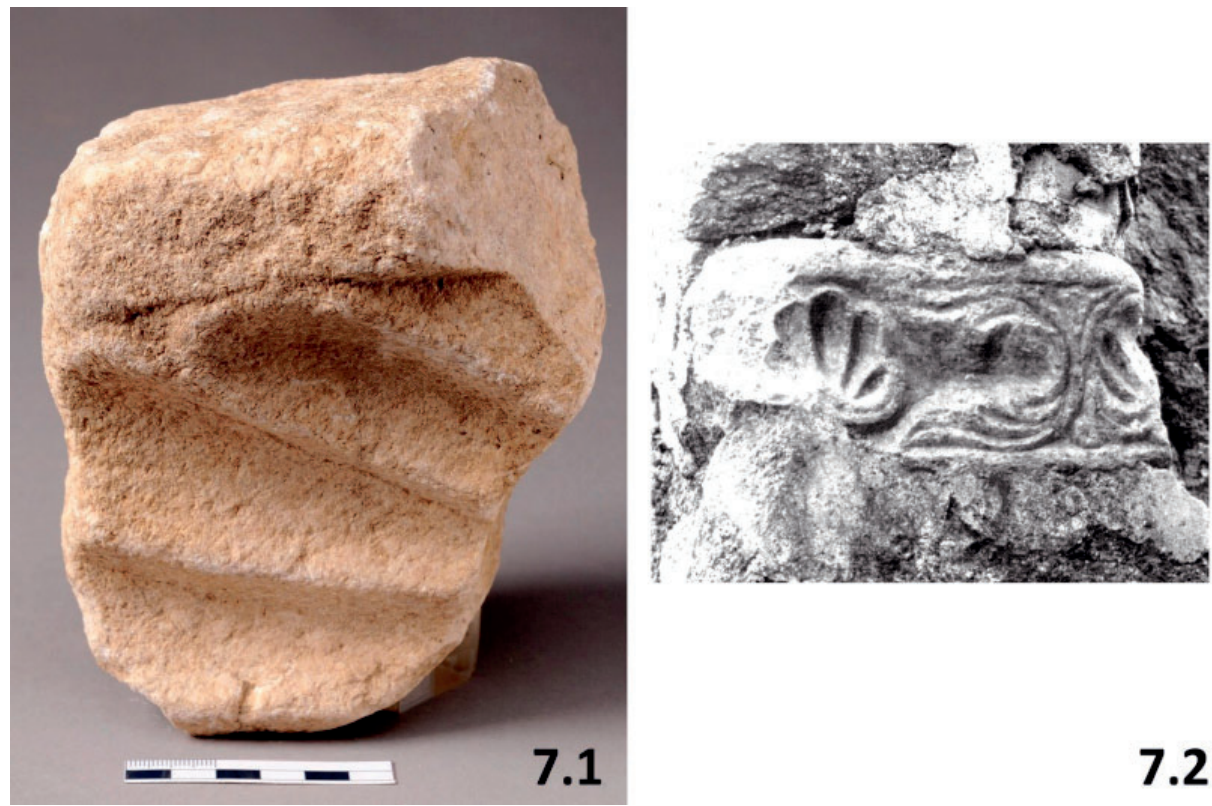

Figura 7: Fragmento decorado con venera de La Solana I (7.1, Museo Arqueológico Regional) y pieza de San Pedro de la Mata (7.2, Luis Caballero Zoreda).

presenta aparentemente un corte en su margen izquierda y sus dimensiones son las siguientes: $(23,5)^{11} \times 18$ $\mathrm{x} 11,5 \mathrm{~cm}$

Impostas idénticas en diseño, tipología, soporte y medidas proceden de Toledo ${ }^{12}$, de San Pedro de La Mata (Casalgordo, Sonseca), del yacimiento de Los Hitos (Arisgotas, Orgaz) y de edificios de la aludida pedanía orgaceña (Fig. 6) ${ }^{13}$

2. MAR DSZ5795 2009-14-03. Fragmento decorado con motivo avenerado incompleto compuesto de tres gallones (Fig. 7.1). Mármol o caliza marmórea de grano grueso. Las mutilaciones sufridas por la pieza impiden determinar con certeza si se trata de un fragmento de imposta análogo al anterior o si pertenece a otro tipo de elemento, aunque nos decantamos por la primera hipótesis $(14,5) \times(12) \times(10) \mathrm{cm}$.

Orgaz, Toledo). Se conocen afloramientos de caliza marmórea en el término toledano de San Pablo de los Montes y en los madrileños de Robledo de Chavela, Villa del Prado, Rascafría o Santa María de la Alameda.

11. Las medidas tomadas de piezas con roturas se indican entre paréntesis.

12. Fragmento de friso empotrado en la Puerta del Cambrón (Barroso y Morín, 2007, 435, nº 229 y 230).

13. Los elementos decorativos procedentes de los dos edificios y los existentes en Arisgotas fueron catalogados y estudiados por Luis J. Balmaseda en su tesis doctoral (1998). Siguiendo el sistema de nomenclatura utilizado por éste, los paralelos para la pieza de Móstoles se encuentran en el tipo II de San Pedro de La Mata (M33 y M34), tipo I de Los Hitos (LH5 y LH6) y tipo II de Arisgotas (A2, A8, A9, A10 y A24). A estas podemos sumar otras dos idénticas actualmente en el Museo Visigodo de Arisgotas (Maquedano, 2001: 51 y 64, piezas n 34 y 59).
El motivo de la venera como parte de la decoración de frisos se encuentra en piezas procedentes de Guarrazar (Guadamur, Toledo), San Pedro de La Mata (Fig. 7.2) y en otros elementos decorativos en Los Hitos $^{14}$.

3. MAR. DSZ5796 2009-14-04. Fragmento de friso o imposta decorado con losanges y botones (Fig. 8.1). Caliza. La pieza, de la que teóricamente faltaría la mitad inferior, presenta huellas de mortero que cubren la parte apenas desbastada que iría empotrada en el muro. (19) x (9) x (14) cm.

Se desconocen posibles paralelos para la asociación de rombos y botones en la escultura hispana de este período. Por separado aparecen con relativa frecuencia estos motivos en la escultura altomedieval de Mérida y Toledo ${ }^{15}$.

4. MAR DSZ5798 2009-14-02. Fragmento de cimacio con trifolia sobre arquillo con botones (cara a) y molduras (cara b). Partido por ambas caras, tan solo conserva una esquina (Fig. 8.2). Caliza. (9) x (11) x (4) $\mathrm{cm}$. La pieza iría colocada sobre una columnilla

14. Frisos del tipo V de Guarrazar (G9, G34, G35 y G36), impostas de San Pedro de la Mata (M1 y M2) y fragmento decorativo de Los Hitos (LH35) (Balmaseda, 1998).

15. Según Caballero y Sáez (1999, 169-ss.) los botones son una característica del taller lapídeo de Santa Lucía del Trampal (Alcuéscar, Cáceres), seguramente activo en la ciudad de Mérida. También encontramos el motivo en Toledo en frisos semejantes a los emeritenses (Barroso y Morín, 2007, $719, \mathrm{n}^{\mathrm{o}} 432$ ). Impostas y cimacios con losanges son relativamente comunes en la escultura toledana (Barroso y Morín, 2007, 715, nº 426, 427 y 428). 

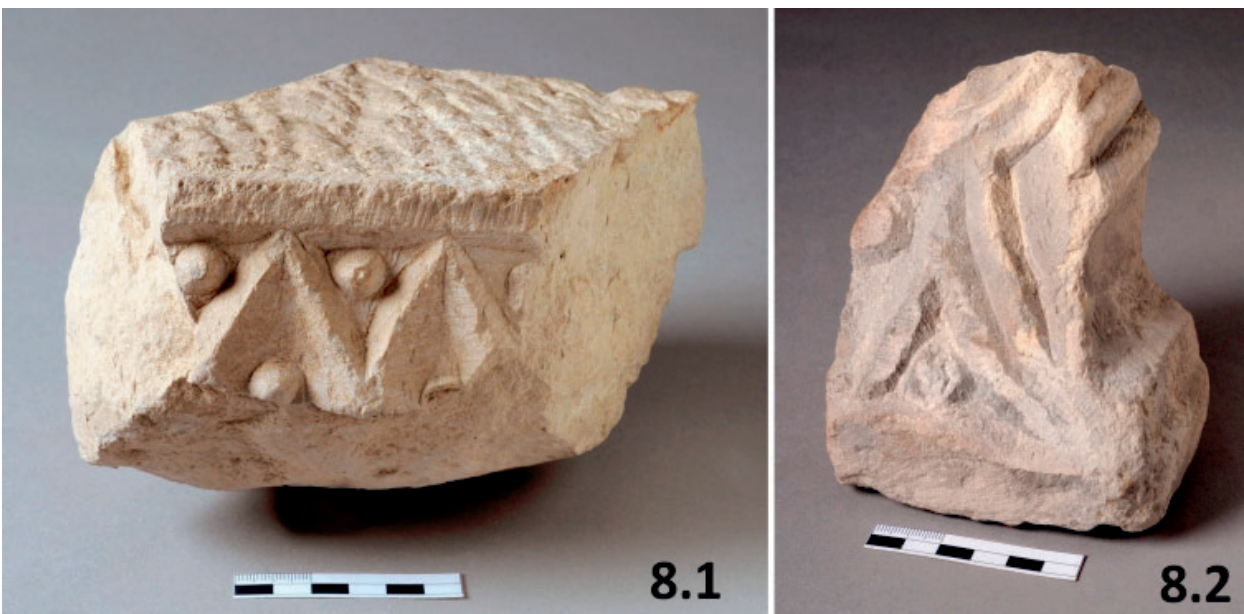

Figura 8: Fotografía de las piezas 3 y 4 (Museo Arqueológico Regional).

(análoga a las piezas $\mathrm{n}^{0} 5,6$ y 8 ) probablemente formando parte de una ventana.

Tanto tamaño como disposición corresponden a un tipo de cimacio conocido en los focos escultóricos emeritense ${ }^{16}$ y toledano, tanto en la propia ciudad $^{17}$ como, de nuevo, en los sitios de Guadamur, Sonseca y Orgaz ${ }^{18}$. Desde el punto de vista decorativo, la trifolia presente en nuestro ejemplar, de diseño y ejecución bastante toscos, hermana bien con las de Guarrazar y Arisgotas (Fig. 9). No obstante desconocemos paralelos idénticos para la trifolia con botones.

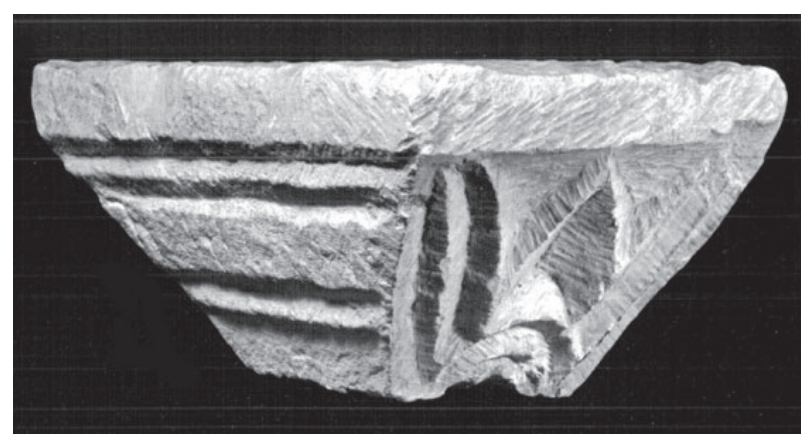

Figura 9: Cimacio procedente de Arisgotas (según Barroso y Morín, 2007).

16. Según Cruz Villalón $(1985,241)$ corresponden a los cimacios de tipo 1 emeritense, representado por las piezas 214 a 223 de su catálogo. Supone que el tipo fue creado en Mérida, a tenor de su significación cuantitativa y del grado de dispersión de los ejemplares.

17. Todas piezas de procedencia desconocida (Barroso y Morín, $2007,679, n^{0} 381$ y 382). Siguen el tipo 1 definido por Cruz Villalón para Mérida.

18. Piezas procedentes de Guarrazar (G6, G7 y G8) y de Los Hitos (LH3) (Balmaseda, 1998). En este caso no se trata estrictamente del tipo 1 de Cruz Villalón (trifolias en lados menores y molduras en los mayores), pues encontramos trifolias en las cuatro caras (ejemplares de Guarrazar) y combinados con un trenzado (ejemplar de Los Hitos).
5. MAR 2009-14-26. Fragmento de columnilla (Fig. 10.1). Mármol. $(7,5)$ x (8) x (3) cm.

6. MAR 2009-14-27. Fragmento de columnilla (Fig. 10.2). Mármol. $6,5 \varnothing \times(7,5) \mathrm{cm}$.

7. MAR 2009-14-28. Fragmento decorativo (Fig. 11.1). Caliza. (9) x (5) x (4) cm. A pesar de su estado fragmentario, el hecho de presentar el plano superior careado y un filete decorativo nos induce a pensar que pueda tratarse de parte de un friso o imposta. Comparado con ejemplares semejantes, iría probablemente decorado con un motivo trenzado.

Piezas con decoración de trenzado aparecen en el mismo ambiente geográfico visto hasta ahora, en San Pedro de la Mata, Los Hitos y Arisgotas (Fig. 11.2) ${ }^{19}$.

8. MAR2005/11211. Fragmento de columnilla con collarino (Fig. 12.1). Caliza. Ø (8) x $5 \mathrm{~cm}$. Abordamos
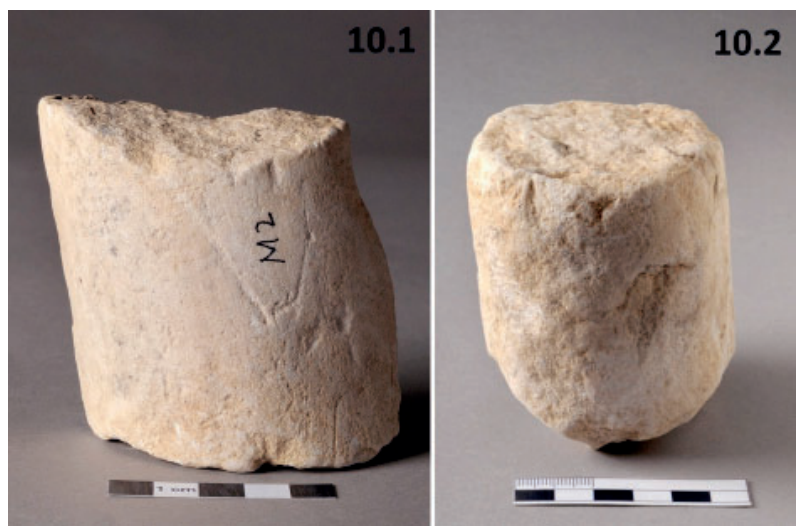

Figura 10: Fragmentos de fustes de columnillas (Museo Arqueológico Regional).

19. Frisos del tipo V de San Pedro de la Mata (M58-M60), tipo III de Los Hitos (LH10, LH12-LH19, LH21-LH26) (Balmaseda, 1998). 


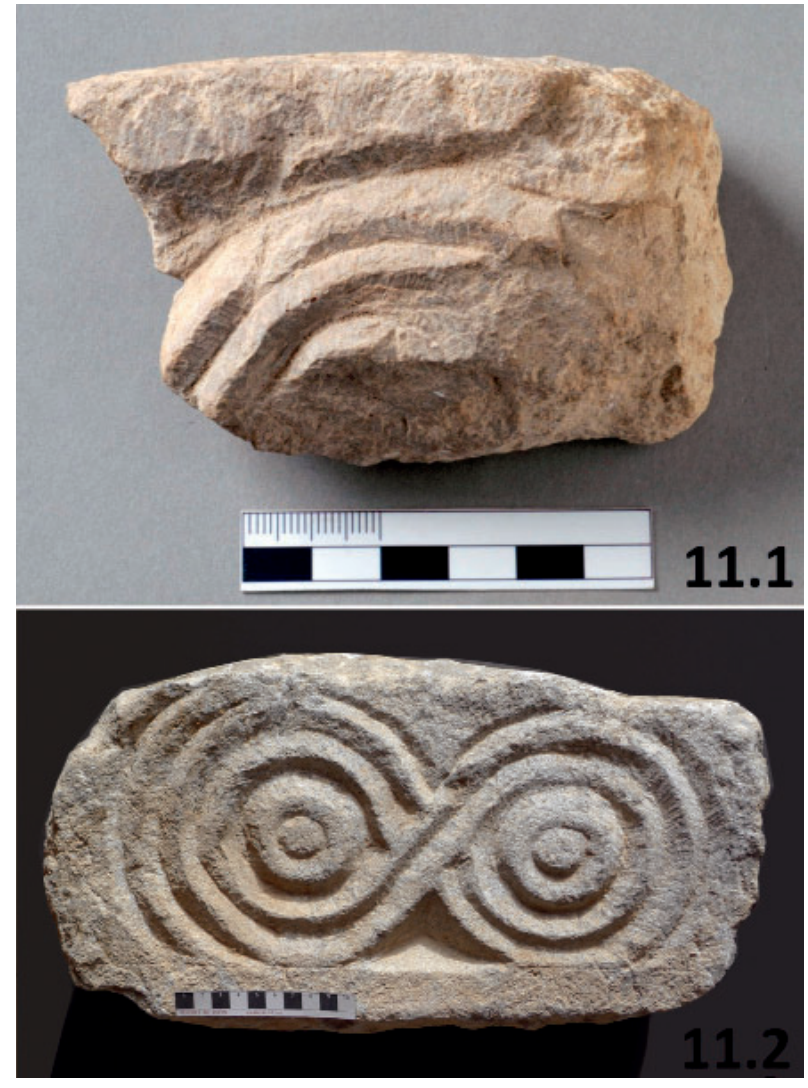

Figura 11: Fragmento decorativo de La Solana I (arriba, Museo Arqueológico Regional) y pieza de Arisgotas (abajo, Alejandro Villa del Castillo). el análisis conjuntamente con las piezas 5 y $6 . \mathrm{El} \mathrm{n}^{\circ} 8$ presenta huellas de talla de un pequeño instrumento de precisión (cincel) aplicado con escasa destreza. Los números 5 y 6 no muestran marcas tan evidentes, encontrándose muy erosionados. Las diferencias señaladas apuntan en los tres casos a distintas adscripciones productivas o temporales.

Los tres fragmentos, uno de caliza y dos de caliza marmórea, en origen formarían parte de piezas enterizas que aglutinaban capitel, fuste y basa. No se trata de cilindros perfectos, sino que su apariencia de fuste circular se consigue por la aproximación de múltiples planos rectos. La mayoría de los ejemplares de este tipo han aparecido descontextualizados o reutilizados en obras posteriores, por lo que en este caso pudieron desempeñar distintas funciones, como parteluces en ventanas o soportes de mesa de $\operatorname{altar}^{20}$.

Algunas columnillas completas aparecidas en la ciudad de Toledo pueden ofrecer una idea de la composición original de los ejemplares aquí estudiados (Fig. 12.2) (Barroso y Morín, 2007, 543, no 293 y 294).

\section{III.2. CONSIDERACIONES PRODUCTIVAS, CRONOLÓGICAS} E INTERPRETATIVAS

El conjunto lapídeo analizado presenta claras concomitancias tipológicas, decorativas y de materia
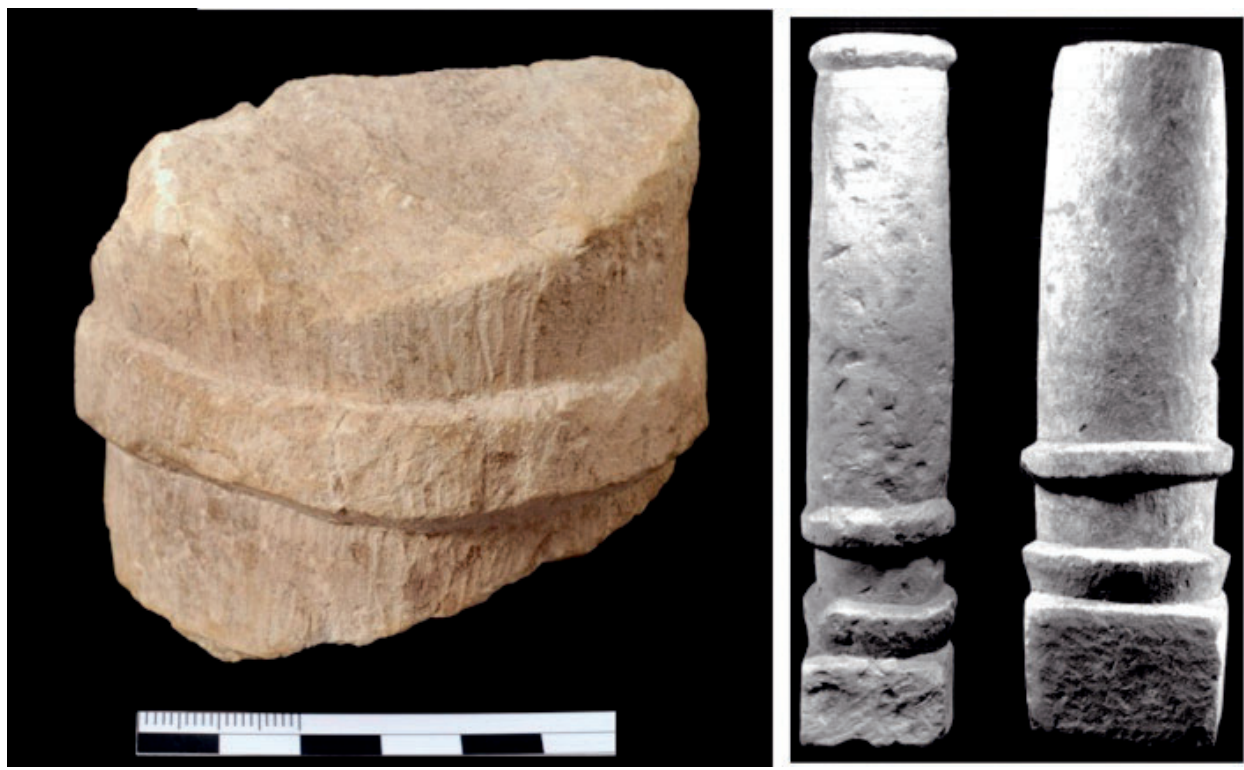

Figura 12: Fragmento de fuste de columna con collarino (pieza 8, izquierda, Museo Arqueológico Regional) y ejemplares toledanos completos de rasgos similares (derecha, según Barroso y Morín, 2007).

20. Tipología definida por Sastre $(2012,122)$ «altar de ara de tradición romana y cuatro soportes laterales», presente, entre otros, en la basílica de Casa Herrera (Mérida) y en Santa Lucía del Trampal (Cáceres). 
prima (mármol o caliza marmórea de grano grueso y caliza de tonalidad oscura) con producciones restringidas a la ciudad de Toledo y su hinterland. Allí encontramos un horizonte productivo muy concreto cuyas piezas presentan el denominador común de constituir frisos-imposta decorados con roleos, hojas y frutos de distinta naturaleza (Balmaseda, 1998; Caballero, 2013, 197-ss.). Los ejemplares de más cuidada factura aparecen en Toledo y Guarrazar, seguidos por el grupo de Sonseca-Orgaz (San Pedro de La Mata, Los Hitos y Arisgotas), el cual se caracteriza por una cierta esquematización de los motivos y por una talla menos virtuosa. A esta segunda variante adscribimos nuestras piezas 1, 2, 4 y $7^{21}$.

El resto de piezas $\left(n^{\circ} 3,5,6,8\right)$ no presentan las suficientes variables técnicas ni estéticas como para permitirnos adscribirlas a un grupo productivo determinado, aunque serían igualmente compatibles con las manufacturas del aludido taller toledano.

Los grupos decorativos caracterizados por la decoración de roleos se restringían hasta el momento a un área geográfica muy concreta (Toledo, Guadamur, Sonseca y Orgaz). Las piezas recuperadas en La Solana I constituyen la primera evidencia de la actividad de los talleres que trabajaron en los centros toledanos de Guadamur-Sonseca-Orgaz al Norte del río Tajo ${ }^{22}$. El conjunto se desmarca (por sus rasgos de taller y por el tipo de soporte geológico) de otro grupo de piezas más o menos coetáneas de la Comunidad de Madrid, caso de los elementos reutilizados en construcciones de Talamanca del Jarama (Barroso y Morín, 2006) e iglesia de Valdeolmos (Marqués de Lozoya, 1940).

El material escultórico analizado en el presente trabajo carece de un contexto arqueológico cerrado y bien articulado. Esto hace necesario el empleo de la comparación tipológica como herramienta para afinar la cronología de los elementos. Existen sin embargo dos problemas de partida: la falta de certeza acerca de la contemporaneidad del lote y la ausencia de consenso entre los especialistas a la hora de fechar los grupos escultóricos con los que hemos establecido relaciones.

La actividad del taller escultórico de San Pedro de la Mata y Los Hitos (al que hemos adscrito las piezas $n^{\circ} 1,2,4$ y 7 ) tiene sus propios problemas a nivel de interpretación cronológica y recibe fechas

21. La relación entre dos de las piezas anteriormente publicadas ( $\mathrm{n}^{\circ} 1$ y 3 ) con relieves de Arisgotas había sido propuesta con anterioridad (Barroso y Morín, 2006, 297).

22. En el pequeño museo de la iglesia de la finca de Granja de Retortillo (Burgos) se conserva un fragmento de imposta perteneciente al taller de San Pedro de La Mata. Las razones de su presencia en tierras tan septentrionales son difíciles de determinar. entre el último tercio del siglo $\mathrm{VII}^{23}$ y los siglos VIII-IX ${ }^{24}$.

Una vez analizados los parámetros funcional y cronológico de las piezas objeto del presente estudio surge la siguiente pregunta: ¿cuáles fueron las características constructivas y funcionales del edificio o edificios para los que fueron creadas? La respuesta se enfrenta a varios obstáculos. En primer lugar, el que se deriva de la escasa definición del contexto de procedencia de los elementos aparecidos en La Solana I. Además, es posible que una de las piezas $\left(\mathrm{n}^{\circ} 1\right)$ presente huellas de una adaptación posterior. En segundo lugar, salvo el lote constituido por las piezas $\mathrm{n}^{\circ} 1,2$, 4 y 7 , no es posible asegurar la contemporaneidad de todos los materiales (distintos soportes y tipologías decorativas). $\mathrm{Y}$ en tercer lugar, el grupo de elementos ornamentales que nos han servido de referencia (Toledo, La Mata, Los Hitos y Arisgotas) carece en todos los casos de un contexto arqueológico primario. Todos

23. San Pedro de La Mata es situado a finales del siglo VII como una derivación de las piezas de Guarrazar, datadas por su aparición conjunta con las coronas y con la lápida de Crispinus (693) (Camps, 1940, 501). Sigue esta propuesta Schlunk $(1947,266)$, para quien este tipo de decoraciones de «tallos con palmetas y racimos» llegaría a la corte toledana a mediados del s. VII procedente de Bizancio, argumento al que suma una noticia antigua sobre la existencia de un 'letrero' en La Mata que rezaba «Wamba me fecid» (por tanto, 672-681). Valorando una muestra más amplia que la de sus predecesores (integrada por las piezas de Guarrazar, La Mata, Los Hitos y Arisgotas) Balmaseda continúa con esta propuesta (Balmaseda, 2006, 289). Se pregunta si las piezas de inferior calidad podrían corresponder a una reconstrucción mozárabe en el caso de La Mata, hipótesis que no es aceptada por Barroso et alii (2012, 287-288). Estos autores datan el grupo en su totalidad en el siglo VII y consecuentemente también las dos piezas de La Solana (piezas 1 y 3) que aparecen en su trabajo sobre la escultura de la Comunidad de Madrid (Barroso y Morín, 2006, 297).

24. Las afinidades estéticas de los frisos de Guarrazar con decoraciones hispanomusulmanas fueron ya advertidas por Camps (1940, 501 y 572). A partir de un modelo explicativo rupturista o «mozarabista», que postula que parte de las producciones arquitectónicas y escultóricas hasta el momento consideradas del siglo VII no serían tales sino que corresponderían a la importación de modelos sirio-orientales a partir de mediados del siglo VIII, la fecha de los talleres que nos sirven de referencia aparece retrasada en más de un siglo. De este modo Cruz Villalón (2000, 271-272) utiliza como paralelo para los racimos de uva la redoma islámica conservada en la catedral de Astorga. Hoppe (2004, 360) interpreta el motivo de la anilla a través de la cual campean los roleos como una abstracción de la vegetación colocada «a espaldera» en las celosías de un jardín, detectando en las mismas una clara influencia islámica. Finalmente Caballero $(2013,197)$ supone la existencia de frisos-imposta como evidencia de la introducción de una arquitectura abovedada introducida en la península en los primeros siglos de la presencia islámica. 
ellos se encontraron reutilizados en edificios de fábrica posterior o descontextualizados ${ }^{25}$.

Teniendo en cuenta las limitaciones aludidas, no nos encontramos en disposición de definir la funcionalidad del edificio para el que fueron concebidos los materiales aquí analizados en base a los datos disponibles. Recientemente, Moreno Martín (2008, 40) llamaba la atención acerca del riesgo de asociar de forma automática la aparición de piezas decoradas con la identificación de edificios de uso religioso si esta circunstancia no ha sido confirmada por la arqueología. Ese riesgo existe en el caso abordado en este trabajo, si bien el problema podría no solventarse ni siquiera con la ejecución de excavaciones arqueológicas en el sitio. A estos interrogantes se suman otros fundamentales a nivel productivo: ¿se trasladó el taller de La Mata - Los Hitos al lugar del hallazgo de las piezas o por el contrario éstas fueron trasladadas una vez talladas? ¿Fueron estos materiales concebidos para el hipotético edificio de La Solana I o reutilizados en el mismo? Parece prudente esperar a que la realización de excavaciones arqueológicas en el sitio aporte nuevos datos acerca de la decoración, funcionalidad y características constructivas del edificio para dar respuesta a estos $\mathrm{y}$ a otros interrogantes.

\section{ANÁLISIS DE LA DOCUMENTACIÓN HISTÓRICA}

Como antes se ha señalado, no se tiene constancia de la existencia de asentamientos aldeanos en el valle del arroyo de El Soto durante el periodo altomedieval al margen del reducido núcleo identificado en La Solana I, ocupado hacia la segunda mitad del siglo VIII d.C.

Unos 1.800 metros al Norte de La Solana se alza la fortaleza de Calatalifa, identificada con la que aparece en las fuentes islámicas en la primera mitad del siglo X (Rodríguez Morales, 2007). Las intervenciones arqueológicas allí desarrolladas hace tiempo han permitido esbozar el trazado de una parte del recinto defensivo, en el que se distinguen «dos murallas construidas con distinto aparejo y dirección» y que encierran un ámbito de unas cuatro hectáreas (Pérez, 1990, 142). Las estructuras domésticas documentadas (en su mayoría silos) proporcionaron abundante vajilla que en su mayoría debe fecharse entre los siglos X y XIII (Retuerce, 1984). A falta de otros documentos arqueológicos, la reconstrucción histórica del poblamiento de

25. En San Pedro de La Mata todas las impostas que hasta hace unos años decoraban las ruinas del edificio estaban recolocadas (Balmaseda, 1998, 310). Los frisos que aparecieron embutidos en una pilastra en el edificio de Los Hitos estarían, en nuestra opinión, igualmente reutilizados (imagen en Balmaseda, 1998, vol. II, LH22 y LH 21). Luis J. Balmaseda $(2006,293)$, su excavador, opina que se encuentran in situ. esta porción de territorio debe acudir pues a las escasas noticias proporcionadas por fuentes escritas bastante posteriores.

Las más antiguas referencias documentales al poblamiento existente en esta zona se remontan a inicios del siglo XIII. La primera noticia, fechada el año 1221 , consiste en una venta de propiedades muebles e inmuebles pertenecientes hasta ese momento a Doña Inés de Segovia ${ }^{26}$. Esta rica propietaria vende a los monjes de la encomienda de Uclés todo lo que posee en Añe, Alboera y Fuente Castellana en término de Segovia («in Fane et in toto termino de Segovia») y Arroyo de Viñas en la Transierra, «in toto termino ultra serra» (Rivera Garretas, 1985, 295) ${ }^{27}$.

Una segunda referencia es de 1270 , en la carta por la que Alfonso X confirmaba la donación hecha por el concejo de la ciudad de Segovia a don Garci Martínez, Notario Mayor del reino de Castilla, de un término denominado Viso de Calatalía ${ }^{28}$. En él aparecen tres vecinos de Arroyo de Viñas (Arroy de Vinnas) (dos de ellos niños), que fueron testigos del amojonamiento de dicho término ${ }^{29}$, así como la cita de un arroyo (la carcava de los aujones), hoy del Aguijón o de los Ahijones, perteneciente a su jurisdicción:

...et desi la cárcava a ayuso assi como llega a Guadarrama et esta en fruent de part allend de Guadarrama la cárcava que dizen de los avjones que es termino de Arroy de Vinnas. (....)

Testigos ante quien moionaron estos cavalleros sobredichos esta heredat: Roy Pérez, fijo de Romo; Dias Sánchez, fide don Sanch Estevan; Gonçalvo Royz, fijo de don Rodrigo; Alvar Luchas; Ferrand Garcia; lohan Benitez; Martin, sobrino de Moraleia la mayor; Domingo fide don Sancho de Arroy de Vinnas; Pedro Caro, fide don Gria de Arroy de Vinnas; Martin Yuannes de Arroy de Vinnas.

26. En la primera edición del Mapa Topográfico Nacional (1877) figura un Camino de Doña Inés al SE de Móstoles, al Sur de la carretera de Extremadura. Probablemente tiene relación con el nombre de la remota propietaria segoviana, puesto que aparece ya en un documento de 1589 (Archivo Histórico de Protocolos de Madrid. Protocolo 32.668, folios 32-42v.).

27. Tumbo de Ucles, liber III, 28, p. 271: «De lo que vendio Dona Ignes de Segovia in Fane et in Albufera et in todo termino de Segovia et in Arroyo de Viñas (era 1259).

Cognoscent presentes et sciant posteri quod ego dompna Agnes vendo/ fratribus de Ucles totum mobile et inmobile quod/ habeo in Albofera et in Ponte Castellana et in toto termino de Secobia et/ in Arrroyo de Vinnas et in toto termino ultra Serra. Vendo inquam hec/ omnia supradicta fratribus supradictis cum omnibus...»

28. Villar, 1990, 290-92, Documento $\mathrm{n}^{\mathrm{o}} 181$.

29. El hecho de que participasen estos tres vecinos de Arroyo de Viñas como testigos o confirmantes del amojonamiento se explica porque el mismo debía realizarse en conformidad con los concejos de las aldeas circundantes. Obviamente, el término que tuviera Arroy de Viñas lindaba con el nuevo que se amojonaba, llamado el Viso de Calatalia. 


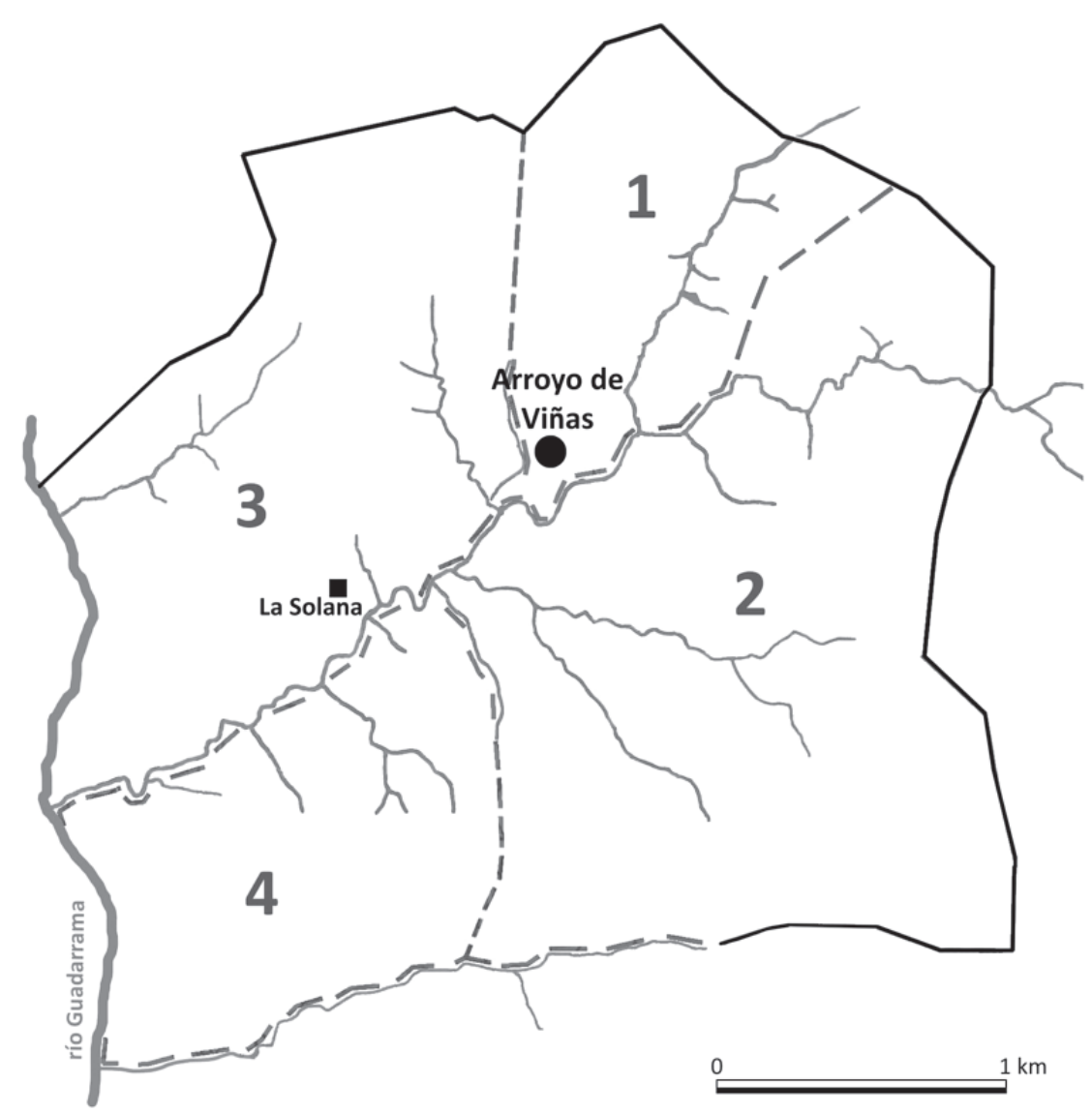

Figura 13: Esquema de la división zonal del término de Arroyo de Viñas tras su despoblación.

En 1302, las Ordenanzas del concejo de Segovia ${ }^{30}$ (González Couto, 1997, 279) vuelven a aludir a la $c a-$ rrera que va de Arroyo de Viñas a Calatalia.

A finales del siglo XIV, en 1391, algunos vecinos de Móstoles vendieron varias suertes de tierra de las que había repartido previamente el concejo ${ }^{31}$. El documento describe una serie de parcelas ubicadas en varios parajes o fondos distintos, y en tres de ellos se cita el camino de Arroyo de Viñas. Es probable que la aldea se hubiera despoblado o venido a menos perdiendo su autonomía tiempo antes, siendo gestionado su territorio por el concejo de Móstoles.

El 29 de julio de $1462^{32}$ el concejo de Móstoles tomó a censo perpetuo o enfiteusis la dehesa de Arroyo de Viñas, que entonces pertenecía a la

30. Archivo General de Simancas. Cámara de Castilla. Pueblos. Legajo 19, documento $\mathrm{n}^{\mathrm{O}} 43$ (es un traslado realizado el 12 de julio de 1409 , englobado en una carta de poder general para pleitos, del 20 de octubre de 1500) / Diversos de Casti1la. Legajo 10, documento ${ }^{\circ}{ }^{29}$. Archivo Histórico Nacional. Diversos. Concejos y ciudades. Legajo 202, folios 6-39 (copia de 1787).

31. Archivo Histórico Nacional. Clero. Secular-Regular. Carpeta 3.118 , doc. 17 .

32. Archivo Histórico de Protocolos de Madrid. Protocolo 32.711. Año 1786, folio 185 . encomienda del hospital de Sancti Spiritu de la ciudad de Segovia ${ }^{33}$.

El término de la aldea de Arroyo de Viñas acabaría dividido grosso modo en cuatro grandes zonas con el despoblado en el centro. Esos bloques serían: la heredad de la Encomienda de Paracuellos de los freires de Uclés (al NE), las Carrasquillas (al SE, zona en la que se hicieron repartos entre vecinos de Móstoles), la Dehesa de Arroyo de Viñas (al NO) y el Monte de San Martín (al SO).

La distancia existente entre las localidades de Arroyo de Viñas y Móstoles (menos de cinco kilómetros en línea recta) testimonia la densa trama dibujada por los asentamientos aldeanos en su configuración original, presumiéndose bajos niveles de jerarquización. Es significativa la reducida y pareja extensión de sus respectivos términos antiguos, herencia del periodo en el que ambos núcleos gozaron de un estatus y de unos efectivos demográficos relativamente equilibrados.

33. Archivo Histórico Provincial de Toledo. Sección de Hacienda. Catastro de Ensenada. Legajo H-411 (Respuestas Generales, $n^{\circ} 26$ ); legajo H-413 y legajo H-414 (relaciones de bienes, ingresos y gastos del concejo). 
La primera referencia a posibles iglesias, ermitas o edificios de culto en este término aparecen en las Relaciones Topográficas de Felipe II (año 1576), bastante tiempo después de que la aldea de Arroyo de Viñas hubiera desaparecido (Alvar, 1994). Los vecinos de Móstoles respondían así a la pregunta número 51 del cuestionario:

\begin{abstract}
A los cinquenta y uno, que en el término desta villa está una hermita de Nuestra Señora de Arroyo de Viñas; y llámase así por estar en la ribera y arroyo que está dicho; es de mucha deboción, y adonde cada un año, por el día de San Marcos, se juntan en procesión esta villa y la de Arroyo de Molinos, y la de Sazedón, y Çarçuela, y Odón, y Navalcarnero, y la procesión desta villa las a de rrecibir a todas, y ninguna puede entrar antes quella, y a la partida las a de despedir a todas, y sale la postrera porque está en su jurisdición; tiene alguna renta que podrá valer un cahiz de pan, y lo demás provee el concejo, y la tiene bien rreparada por su deboción...
\end{abstract}

Los diversos nombres con que aparecerá citada esta ermita a partir de entonces puede ser la causa por la que a inicios del siglo XX se defendiese la existencia de dos ermitas en la zona: la de Nuestra Señora de Arroyo de Viñas (también llamada a partir de cierto momento Nuestra Señora de la Salud) y la de San Marcos (Ocaña, 1908). Lo cierto es que en la ermita (que probablemente había sido la parroquial de la aldea de Arroyo de Viñas) se celebraba cada año la llegada de la primavera el día de San Marcos Evangelista. Con el nombre del santo aparece citada en varias ocasiones a lo largo del siglo XVII ${ }^{34}$, y con ese nombre se conoce además al paraje en el que se encontraba. El Pradillo de San Marcos aparece en algunas ediciones del Mapa Topográfico Nacional inmediatamente al Oeste del punto en el que el arroyo de Pelete desagua en el de El Soto, junto al lugar donde, como ya se ha referido, se identificó arqueológicamente un despoblado pleno y bajomedieval.

A finales del siglo XVII parece mudar de advocación al aparecer como Nuestra Señora de la Salud $d^{35}$, aunque los informes de las visitas pastorales al partido de Canales y Escalona, que se conservan en el Archivo Diocesano de Toledo, no mencionan esta advocación hasta el s. XVIII. En el Catastro de Ensenada (1753) se precisa «alias de Rodiviñas», confirmando que se trataba del mismo santuario al que se refería la encuesta

34. Archivo de la Real Chancillería de Valladolid. Protocolos y padrones. Caja 152, $\mathrm{n}^{\circ} 1$ (concejo del 20 de enero de 1640), $\mathrm{n}^{\circ} 3$ (concejo de 28 de octubre de 1646), $\mathrm{n}^{\circ} 4$ (concejo del 14 de enero de 1652) y n 5 (concejo del 20 de febrero de 1655). Archivo Histórico de Protocolos de Madrid. Protocolo 32.688, folios 55-56 (año 1665) / Protocolo 32.694, folios 281-288 (1685) / Protocolo 32.695, folios 96-97 (1697).

35. Archivo Histórico de Protocolos de Madrid. Protocolo 32.694, folios 7-8v. Documento de 1688. del siglo $\mathrm{XVI}^{36}$. La fábrica de la ermita tenía en 1753 una modesta dotación. En 1783 el concejo invirtió 556 reales en obras de reparación en la misma ${ }^{37}$, y por una escritura de 1786, se sabe que tenía agregada la cofradía de Ntra. Sra. de Arroyo de Viñas ${ }^{38}$.

En 1792, el vicario Vicente de Carrancio proporciona noticias relevantes sobre el edificio y la clase de eventos que allí se celebraban. Además la situaba a unos tres cuartos de legua del pueblo (los cuatro kilómetros que hay entre Móstoles y el paraje de San Marcos).

\begin{abstract}
«La de Nuestra Señora de la Salud, conocida por el nombre de Rodeviñas, esta tres quartos de legua del pueblo; no tiene casi vienes. Mande se hiciese un tabique en los postes de la entrada con su puerta, porque teniendo al un lado la cocina, y un quarto al otro, donde comen los de justicia el dia de la funcion, era indecente pasasen con la comida a vista del altar. Este es despoblado, se llamaba Mentercosa, esta al oriente, junto al rio Guadarrama; al poniente no fixo el de Mostoles, lo dicho lo mismo de Sacedon de Canales. Alli me dixeron se juntaban los pueblos del territorio quando hacian Junta o Consejo de la Tierra en tiempos antiguos».
\end{abstract}

Unos años más tarde, en 1796, una madrileña fundó una capellanía para decir misas en esta ermita ${ }^{39}$. Todo indica que la Guerra de la Independencia contra los ejércitos napoleónicos pudo precipitar la ruina del edificio. En 1820, según noticias recogidas por Juan Ocaña, fue desmantelada la ermita y las imágenes de Nuestra Señora de la Salud y de San Marcos se trasladaron a la iglesia parroquial de Móstoles.

En la Ilustración Artística (3 de mayo de 1897), se recoge una tradición local que alude a la ermita y al significado que había tenido aquel lugar para los vecinos:

"Cuando durante la guerra pasaban los franceses por Móstoles, sus vecinos se refugiaron en la ermita de Nuestra Señora de la Salud, situada a unos tres kilometros del pueblo, en el pradillo de San Marcos, y a orillas de un arroyo. A esta ermita iban en romería los de Móstoles, el 25 de Abril, festividad de San Marcos evangelista, y se hacía una distribución

36. Archivo Histórico Provincial de Toledo. Sección de Hacienda. Catastro de Ensenada. Legajo H-414 (folios 1.005 v-1006). En 1786, Félix de San Martín reconocía un censo redimible que tenía a favor de la fábrica de dicha ermita, y la llamaba indistintamente de Nuestra Señora de la Salud o de Nuestra Señora de Arroyo de Viñas (Archivo Histórico de Protocolos de Madrid. Protocolo 32.711, folios 190-191, tercer cuaderno del legajo).

37. Archivo Histórico Nacional. Consejos. Legajo 27.646, expediente 13

38. Archivo Histórico de Protocolos de Madrid. Protocolo 32.711, folios 190-191 ( $3^{\text {a }}$ foliación).

39. Archivo Diocesano de Getafe. Móstoles, Capellanías, 1/2 $-16$. 
de pan y queso a cada vecino que asistia a la fiesta, pero también se llevaba una cadena para traer con ella atado al pueblo al que se emborrachaba o alborotase, con lo cual no había borracheras ni pendencias».

\section{DISCUSIÓN}

Una vez presentados los datos disponibles sobre el yacimiento arqueológico de La Solana I y la información existente sobre el poblamiento de la zona en época premoderna, se discutirán en este apartado algunas de las implicaciones que suscita la presencia de distintos yacimientos en este tramo del valle del arroyo de El Soto.

\section{V.1. IDENTIFICACIONES}

Es necesario, en primer lugar, tener claras las diferencias existentes entre la aldea de Arroyo de Viñas (documentada desde inicios del XIII), que da nombre al término, y la identificación de los posibles edificios de culto presentes en el valle. Teniendo en cuenta las distancias señaladas por los textos entre la ermita de Nuestra Señora de la Salud (equiparada a N.S. de Arroyo de Viñas o Rodeviñas, en el Pradillo de San Marcos) y el pueblo de Móstoles (tres cuartos de legua, según la información proporcionada por el visitador eclesiástico de 1792 y los tres kilómetros a los que alude la Ilustración Artística de 1897), es posible argumentar que en ellas se aludiría a un emplazamiento más cercano a Móstoles de lo que se encuentran los restos arqueológicos de La Solana I.

Se concluye en primer lugar, por tanto, que existieron dos edificios de culto en la zona antes del siglo XIV: uno altomedieval y otro posterior (de los siglos XII-XIII), que pudo tener carácter parroquial para la aldea de Arroyo de Viñas. No es posible identificar los restos arqueológicos de La Solana I con el edificio de culto citado en las fuentes del siglo XVI en adelante, ni hay pruebas para sostener que ambos hayan podido estar en uso al mismo tiempo.

Tampoco hay datos que permitan remontar a época altomedieval el origen de la aldea de Arroyo de Viñas, identificada con el yacimiento denominado San Marcos, un kilómetro aguas arriba del de La Solana I. El material cerámico visible en superficie asociado al despoblado de la aldea medieval se adscribiría fundamentalmente a los siglos XIII-XIV, aunque también se registran piezas de época romana y moderna. Los materiales muebles reconocibles en superficie en La Solana I sí corroboran la cronología altomedieval en este caso, tanto los elementos de escultura decorativa como la cerámica.

Cuestión más complicada es tratar de determinar el origen y el final del conjunto edificado de La Solana I. Por cuanto respecta a la fecha de construcción, los datos no consienten terciar en el debate sobre la cronología de este tipo de edificios (Chavarría, 2010). Los materiales cerámicos avalan la existencia de una ocupación doméstica al lado del edificio en piedra en torno a la segunda mitad del siglo VIII. La asociación existente entre ambos elementos no puede esclarecerse con los datos disponibles (¿se yuxtaponen o superponen?). Los indicios de posibles silos o cabañas de suelo rehundido no parecen ajustarse al tipo de huellas que habría generado la actividad del grupo constructor del edificio. El tipo de estructuras que se intuye en el subsuelo y los residuos que allí se depositaron parecen testimoniar el establecimiento de alguna familia o comunidad poco numerosa durante un plazo de tiempo no superior al medio siglo. Por lo que respecta al final del edificio tampoco hay nada seguro. La homogeneidad estilística de las piezas arquitectónicas decoradas y la ausencia de otra clase de material más reciente sólo apunta a que pudo no sufrir reformas o modificaciones posteriores que dejasen huella.

En cuanto a la interpretación funcional del conjunto, las pruebas materiales no son definitivas a la hora de asegurar que se haya tratado de una iglesia, aunque ésa parece la opción más probable. Sería difícil de argumentar el funcionamiento en este paraje de un edificio de carácter exclusivamente civil con elementos arquitectónicos de prestigio como los antes descritos.

El análisis de la trama de caminos secundarios que aparece en la primera edición del Mapa Topográfico Nacional (1877) revela la existencia de dos nodos en el tramo medio-bajo del arroyo de El Soto (Fig. 14). El que se sitúa un kilómetro aguas arriba de La Solana I coincide con la localización del despoblado identificado con el yacimiento arqueológico bajomedieval de San Marcos (B). La trama viaria suele revelarse como uno de los rasgos más estables del paisaje rural. Algunos de sus elementos perduran como articuladores del parcelario siglos después de haber perdido su función original, y en este caso delatan todavía el emplazamiento de una pequeña aldea que se despobló posiblemente a finales del siglo XIV. El nodo C podría señalar un punto muy estable de vadeo del arroyo en el camino de Móstoles a Calatalifa o incluso un segundo núcleo residencial o barrio de la aldea de Arroyo de Viñas. Un paralelo para esa posible duplicidad de asentamientos se reconoce en el vecino término de Arroyomolinos, donde existe constancia de dos núcleos habitados durante los siglos XIII-XIV a una distancia similar, menos de dos kilómetros ${ }^{40}$.

40. San Pedro de Chozas del Arroyo de los Molinos puede haber sido el establecimiento de repoblación de los segovianos del que existe constancia documental. El otro, tal vez el asentamiento original de Chozas, se documentó arqueológicamente en el paraje llamado Tierras de la Iglesia, aguas abajo del primero, frente al pueblo actual, sobre un asentamiento altomedieval abandonado en las postrimerías del siglo VIII d.C. 


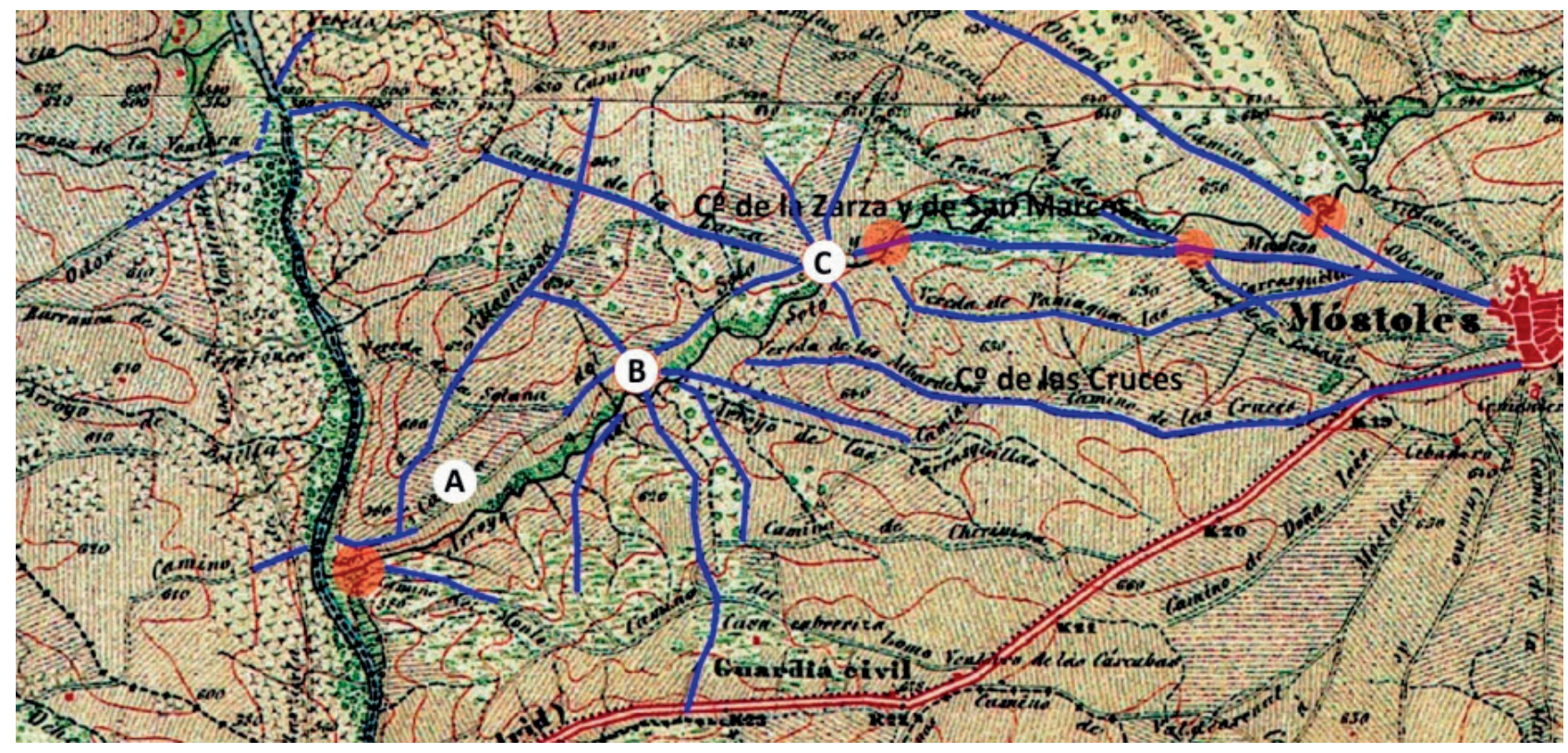

Figura 14: Primera edición (1877) del Mapa Topográfico Nacional con el sistema viario tradicional resaltado. Los nodos pueden corresponder al emplazamiento de despoblados, aunque también a puentes o vados. Se señalan el sitio de La Solana I (A), la aldea de Arroyo de Viñas (B) y el punto donde se podría presumir la existencia de un vado estable del arroyo o de un segundo núcleo habitado no identificado en la documentación $(\mathrm{C})$.

\section{V.2. El poblamiento RuRal entre la Alta y la Ple- NA EDAD MEDIA}

Apenas se dispone de información arqueológica acerca de la aldea que aparece citada desde inicios del siglo XIII en la documentación histórica con el nombre de Arroyo de Viñas. De aceptarse su identificación con los vestigios materiales del yacimiento denominado San Marcos, es probable que esa aldea tenga su origen en la reestructuración del poblamiento rural acometida a partir de finales del siglo XII en toda la región, cuando la frontera se desplazó definitivamente hacia el Sur peninsular. El vacío arqueológico detectado en el poblamiento rural entre los siglos X y XII podría achacarse al proceso de concentración demográfica que se atestigua igualmente en otras partes del territorio madrileño (Vigil-Escalera y Quirós, 2013, 397-98). En el caso aquí abordado, esa nucleación debió pivotar sobre la fortaleza de Calatalifa, a menos de dos kilómetros al Noroeste de La Solana I.

Ahora bien, el abandono de todos los asentamientos rurales altomedievales conocidos en la región antes del siglo X no implica por fuerza que sus espacios de trabajo tradicionales fueran amortizados. La congruencia observada entre el emplazamiento elegido para la fundación de los nuevos asentamientos de los siglos XII-XIII y el solar de las aldeas previas (tras un hiato de tres siglos en lo que atañe a usos residenciales) tal vez no responda sólo al dictado de un óptimo aprovechamiento de los recursos del territorio según lógicas económicas campesinas. Esos condicionantes espaciales bien podrían atestiguar la pervivencia plurisecular de determinados usos del espacio agrario de difícil reconocimiento arqueológico. El nombre con el que fue bautizada la aldea (Arroyo de Viñas) parece de hecho testimoniar que esa parte del valle estaba cultivada cuando se estableció allí esa población o cuando se reclamaron derechos sobre ese territorio ${ }^{41}$.

Es posible que el carácter central del edificio de culto de la aldea de Arroyo de Viñas para el conjunto de las comunidades campesinas del entorno tenga igualmente un remoto origen ${ }^{42}$. Jugaba ese papel en la segunda mitad del siglo XVI y sabemos que siguió siendo lugar de referencia para un grupo de aldeas cercanas durante varios siglos más, aunque nada puede decirse con seguridad sobre su origen. El hecho de que en este tramo del valle del arroyo de El Soto se identifiquen los restos de una posible iglesia altomedieval tal vez no sea una mera coincidencia. Como se ha señalado antes en lo tocante a la red de caminos secundarios, ciertas estructuras del paisaje rural gozan de una significativa persistencia. A pocos elementos puede presumírseles mayor estabilidad intergeneracional que al lugar donde se gestionan los asuntos públicos que conciernen como colectivo a un conjunto de

41. Lo mismo ocurre con el valle colindante por el Sur (Arroyomolinos). El asentamiento aparece citado en los textos más antiguos conservados como Chozas del Arroyo de los Molinos, dando a entender que los molinos eran elementos reconocibles del paisaje antes de que se estableciesen allí los repobladores citados en la documentación escrita.

42. La opinión contraria prevalece en la obra de J. González, para quien «con muy pocas excepciones, en todas las poblaciones, las iglesias nacen con la llegada de los cristianos del Norte» (González, 1975, cit. en Retuerce, 2004, 88) o «al Norte del Tajo son contados los pueblos con nombre y nacimiento que no sean castellanos» (González, 1975, 317). 
comunidades aldeanas vecinas. Principal 'ventana' al mundo exterior de la aldea, en esos sitios y en fechas determinadas tiene lugar la mayor parte de la interacción social y económica entre individuos de distintas localidades. No por casualidad será allí donde se celebre una de las festividades más importantes del ciclo agrario.

¿Fué la iglesia de Arroyo de Viñas un referente para las comunidades aldeanas de su entorno inmediato porque ese mismo carácter ya lo había ostentado anteriormente el edificio de La Solana I?, ¿heredó (o suplantó) la nueva las funciones de la anterior? La posibilidad es atractiva, aunque no contrastable a partir de los datos disponibles. Sería necesario poder evaluar el grado de continuidad existente en los usos del paisaje rural, la persistencia de la memoria colectiva y la de ciertos hábitos comunitarios a fin de salvar un periodo histórico sumamente abrupto como el que caracteriza a este territorio entre los siglos IX y XII.

La centralidad del papel desempeñado por las primeras iglesias rurales no se agota en su consideración como centros de culto o incluso como los primeros y más básicos nodos de la estructura administrativa o política del territorio. En esos lugares, bajo el amparo o con la supervisión de la Iglesia, se desarrollaron funciones políticas y económicas de primer orden para el ámbito supralocal hasta fechas relativamente recientes. La gestión mancomunada de asuntos que afectan a un puñado de localidades vecinas es la clave que justifica la significativa durabilidad de elementos que resultan habitualmente opacos a la documentación escrita.

Abogar por el mantenimiento de "hilos de continuidad' en el paisaje rural de estas comarcas entre la Alta y la Plena Edad Media parece, a fin de cuentas, un ejercicio inevitable a la hora de postular la supervivencia de la memoria del edificio de La Solana I y la del conjunto de costumbres y prácticas sociales y económicas que a ella iban aparejada ${ }^{43}$, aunque para ello es necesario vencer la resistencia que ofrecen algunas convenciones historiográficas. Exige cuestionar o matizar, en primer lugar, que estas comarcas sufrieran una merma demográfica significativa tras la conquista islámica. Hace necesario postular también que la población de las numerosas aldeas ocupadas entre los siglos V y VIII d.C. se reagrupó en ciertos puntos desde donde siguieron explotando, siquiera con profundos cambios, sus territorios ancestrales. En tercer lugar requiere asumir que la región no se vació tampoco tras la conquista castellana de Toledo en 1085. Requiere finalmente explicar de manera razonada cuál pudo ser el

43. «Per decifrare il motivo per il quale una chiesa venne fondata in una certa localitá e in un determinato momento e di chi sia stata l'iniziativa (parametri fondamentali per ricostruire le modalitá della costruzione di una rete ecclesiastica rurale) servono indagini a scala territoriale circoscritta e con una relazione piú diretta con le 'strutture' dell'insediamento» (Brogiolo, 2013, 233). Véase también Zadora-Rio (2005) o Catafau (2008). significado de la repoblación que los segovianos hicieron de estas tierras entre los siglos XII y XIV ${ }^{44}$.

La incompleta reocupación del medio rural por grupos de familias de cultivadores que buscan establecer su residencia estable junto a las parcelas cultivadas a diario ofrece una alternativa hipotética. Es posible que el territorio que se apropiaron los repobladores del otro lado del Sistema Central quedara sustancialmente constituido por los vacíos dejados en su retorno a los campos por unas comunidades nativas de costumbres, lengua y religión mayoritariamente islámica. Sólo colectivos potentes y bien articulados como el de la ciudad de Madrid fueron capaces de plantar cara durante los siglos siguientes al expansionismo económico y político de los norteños. Es posible que la documentación escrita conservada nos informe casi exclusivamente sobre los responsables de rellenar esos huecos, y muy en especial de sus promotores y dirigentes, mientras que lo desconocemos casi todo sobre el devenir de los grupos que permanecieron sobre el terreno desde la desarticulación del Imperio romano. Se trata sin duda de un vasto territorio ignoto que la arqueología está en condiciones de explorar durante los próximos años.

\section{CONCLUSIONES}

Toca finalmente sopesar de forma conjunta la documentación reunida sobre los restos arqueológicos del yacimiento de La Solana I.

Del análisis de la escultura decorativa se deduce la existencia de un edificio altomedieval de prestigio, cuya datación podría moverse entre finales del siglo VII y el siglo VIII d.C. Los materiales y el tipo de contexto del que proceden no permiten interpretar con seguridad que se trate de una iglesia, aunque sí constatar que el edificio pertenece a las producciones de un taller que operó en distintos puntos del distrito toledano en un periodo aún difícil de determinar. Ninguno de ellos (Arisgotas, Los Hitos, S. Pedro de la Mata) ha proporcionado todavía elementos suficientes para establecer mayor precisión cronológica ni funcional.

El análisis de los otros materiales de superficie de La Solana revela que al lado del edificio se desarrolló una ocupación doméstica de escasa extensión durante la segunda mitad del siglo VIII, aunque tal vez se pudo iniciar algo antes. También que en su lado Este debe localizarse una necrópolis o algún grupo funerario. No se detecta continuidad en la ocupación de estas parcelas con posterioridad. Los restos de un despoblado

44. Cuando en 1141 Alfonso VII otorgó fuero a Calatalifa se nombró como tenente, encargado da atraer repobladores al territorio, a un tal Sebastián Díaz (Archivo de la Catedral de Segovia. Códices, $\mathrm{n}^{\circ}$ B-329 / Libro de memoria de algunos privilegios, folio 11). Sesenta y siete años después, en 1208, numerosas aldeas segovianas que se nombran en el privilegio de la Bolsilla (Batres, Serranillos, las tres Moralejas y Móstoles - citado ya en 1144 como Turris de Monsteles-) tenían términos propios (González, 1960, tomo 3, 454). 
pleno y bajomedieval distan al menos un kilómetro aguas arriba del arroyo. Es posible que dentro del recinto amurallado de Calatalifa o en sus arrabales se concentrase a la mayor parte de la población de la comarca entre los siglos IX y XII d.C.

La documentación escrita aporta elementos suficientes para reconocer el establecimiento de la aldea bajomedieval de Arroyo de Viñas en este valle. Estaba habitada con seguridad en la primera mitad del siglo XIII, y consta como despoblada desde al menos el XVI. El edificio de culto citado como Nuestra Señora de Arroyo de Viñas constituía desde mediados del siglo XVI el centro de un distrito campesino de cierta entidad. Allí se celebraron las asambleas de un concejo formado por media docena de localidades del entorno (Móstoles, Odón, Sacedón, Navalcarnero, Arroyomolinos, Zarzuela). Por las Relaciones Topográficas de Felipe II conocemos que la gente de las aldeas citadas iba en peregrinación a ese lugar para festejar la primavera el día de San Marcos Evangelista (25 de abril ${ }^{45}$ ). Es probable que se aprovechara también para celebrar una feria de interés comarcal. La noticia de 1792 se refiere a que en el templo o junto a él se celebraba la Junta o Consejo de la Tierra, donde se resolvían asuntos que concernían al citado conjunto de localidades. La época a la que se remonta tal tradición es difícil de determinar. Con el transcurso de tiempo cambiaron sin duda los nombres y el emplazamiento de muchas de esas poblaciones, aunque la memoria y la costumbre hacen de la periodicidad de esos eventos y del lugar de reunión algo sumamente estable. Durante la Guerra de la Independencia la ermita sirvió de refugio para algunos vecinos de Móstoles, derribándose sus restos en 1820 para recuperar materiales constructivos con los que levantar la nueva Casa Consistorial.

En anteriores trabajos (Ocaña, 1908) se supuso la existencia de dos edificios distintos: la iglesia de Arroyo de Viñas (también llamada de la Salud) y la ermita de San Marcos. No hay pruebas fehacientes al respecto de esa posibilidad, ya que ambos nombres se refieren al mismo templo ${ }^{46}$. El visitador eclesiástico de 1792 deja clara su situación a tres cuartos de legua de Móstoles, distancia coincidente con el sitio donde el material arqueológico de superficie revela la probable localización de la aldea desaparecida de Arroyo de Viñas, inmediata a un lugar que aún se denomina Pradillo de San Marcos.

La posible relación entre el edificio altomedieval de La Solana I y la historia posterior del valle tiene de momento una cierta dosis de especulación. No así

45. En toda la comarca se solía peregrinar el día de San Marcos a ermitas existentes en despoblados. La aldea de La Cabeza peregrinaba a Nuestra Señora de Batres (Carranque), la de Camarena a la iglesia de Bobadilla, la de Méntrida a Nuestra Señora de Berciana, o la de Fuenlabrada a la ermita de Fregacedos.

46. Así lo demuestra la documentación exhumada por David Martín del Hoyo en el Archivo Diocesano de Toledo. el funcionamiento de la iglesia (luego ermita) de Rodeviñas como centro referencial para las aldeas de su entorno durante varios siglos.

Sabemos en la actualidad que la configuración territorial de la administración eclesiástica altomedieval es bien diferente de la implantada a partir de los siglos XI-XII y que la mayor parte de las aldeas de época visigoda no dispuso de edificios de culto arqueológicamente reconocibles. La elección del sitio de La Solana I para la construcción de una iglesia o edificio de prestigio a finales del siglo VII o durante el VIII d.C. es congruente con el hecho de que el lugar tuviese relevancia como lugar de reunión para el conjunto de aldeas existente en un radio de 5-8 kilómetros, aunque tampoco cabe descartar que sucediera al revés. La construcción de una iglesia en un sitio desde donde fuera posible dar servicio a un conjunto de asentamientos pudo significar además la imposición de alguna clase de control sobre el sitio de reunión, mercado y celebración de esa macro-comunidad campesina.

No hay datos de momento que permitan dilucidar la historia posterior del edificio de La Solana I. Cuando a inicios del siglo XIII entran en escena los primeros documentos escritos, la iglesia de la aldea de Arroyo de Viñas probablemente había asumido ya un carácter central para un distrito supralocal, tal vez suplantando el papel del anterior edificio altomedieval.

La continuidad funcional de este sitio como lugar de asamblea para un conjunto compacto de comunidades aldeanas vecinas a lo largo de más de mil años constituye una hipótesis verosímil y muy sugestiva, aunque no exenta de problemas.

\section{Agradecimientos}

Los autores agradecen la recopilación documental del historiador mostoleño David Martín del Hoyo y los comentarios y aportaciones críticas de Luis Caballero Zoreda, María de los Ángeles Utrero, Carlos Cauce Cañizares y Juan Antonio Quirós Castillo.

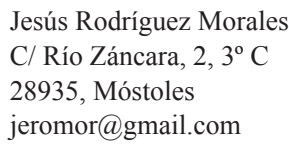

Prof. Dr. Alfonso Vigil-Escalera Guirado

Dpto. de Geografía, Prehistoria y Arqueologia Facultad de Letras

Universidad del País Vasco UPV/EHU

c/ Francisco Tomás y Valiente s/n

01006 Vitoria-Gasteiz

aveg01@gmail.com

Alejandro Villa del Castillo

CSIC

Centro de Ciencias Humanas y Sociales

Despacho 2E13

C/ Albasanz, 26-28

28037 Madrid

alejandro.villa@cchs.csic.es 


\section{BIBLIOGRAFÍA}

ALVAR EZQUERRA, A., 1994, Relaciones topográficas de Felipe II. Madrid. 3 vols. Madrid: CSIC.

BALMASEDA MUNCHARAZ, L.J., 1998: Arte ornamental arquitectónico visigodo en la provincia de Toledo, tesis doctoral inédita, 2 vol., Universidad Complutense de Madrid, Madrid (manuscrito).

BALMASEDA MUNCHARAZ, L.J., 2006: «Algunos problemas de la escultura toledana», en Escultura decorativa tardorromana y altomedieval en la Península Ibérica, Anejos de Archivo Español de Arqueología XLI, 275-298 Madrid.

BARROSO CABRERA, R. y MORÍN DE PABLOS, J., 2006: «La escultura de época visigoda en la Comunidad de Madrid», en La investigación arqueológica de la época visigoda en la Comunidad de Madrid, vol. I, Historiografía y Territorio, Zona Arqueológica, 8, 687-704.

BARROSO CABRERA, R., MORÍN DE PABLOS, J. y CARROBLES SANTOS, J., 2012: «La articulación del territorio toledano entre la Antigüedad y la Alta Edad Media (ss. VI al VIII D.C.), en L. Caballero Zoreda, P. Mateos Cruz y T. Cordero Ruiz (eds.), Visigodos y Omeyas. El territorio, 263-304, Mérida.

BROGIOLO, G. P., 2013: «Paesaggi, insediamenti e architetture tra etá romana e XIII secolo», en G.P. Brogiolo (a cura di), APSAT 3. Paesaggi storici del Sommolago, 165-218, Mantova.

CABALLERO ZOREDA, L., 2011: «Acerca del paisaje arquitectónico hispánico inmediato al año 711 (entre Toledo y el territorio astur y vasco)», Zona Arqueológica, 15.1, 255-271.

CABALLERO ZOREDA, L., 2013: «Producciones constructivas y decorativas. Indicadores cronológico-culturales de la alta Edad Media hispánica», Archivo Español de Arqueología, 86, 187-214.

CABALLERO ZOREDA, L. y SÁEZ LARA, F., 1999: La iglesia mozárabe de Santa Lucía del Trampal. Alcuéscar (Cáceres). Arqueología y Arquitectura, Memorias de arqueología extremeña 2, Mérida.

CAMPS CAZORLA, E., 1940: «El arte hispanovisigodo», en Historia de España dirigida por Menéndez Pidal, Tomo III, 435 - 608, Madrid.

CATAFAU, A., 2008: «L'église comme centre organisateur de l'habitat en Languedoc, Rousillon et Catalogne, $\mathrm{VIII}$ - $\mathrm{XI}^{\mathrm{e}}$ siècles», en Movimientos migratorios, asentamientos y expansión (siglos VIII-XI). En el centenario del profesor José María Lacarra (1907-2007), XXXIV Semana de Estudios Medievales (Estella, 16 a 20 de julio de 2007), 187-229, Pamplona.

CRUZ VILLALÓN, M., 1985: Mérida visigoda. La escultura arquitectónica y litúrgica, Badajoz.

CRUZ VILLALÓN, M., 2000: «El taller de escultura de Mérida. Contradicciones de la escultura visigoda», en Visigodos y Omeyas. Un debate entre la Antigüedad Tardía y la Alta Edad Media, Anejos de Archivo Español de Arqueología XXIII, 265-278, Madrid.

CHAVARRÍA ARNAU, A., 2010: «Churches and aristocracies in seventh-century Spain: some thoughts on the debate on Visigothic churches», Early Medieval Europe, 8 (2), 160-174.

GONZÁLEZ COUTO, F., 1997: Documentos para la historia de San Martín de la Vega: (hasta el año 1500), Ayuntamiento de San Martín de la Vega.

GONZÁLEZ GONZÁLEZ, J., 1960: El Reino de Castilla en la época de Alfonso VIII, 4 Vols., Madrid.

GONZÁLEZ GONZÁLEZ, J., 1975: Repoblación de Castilla la Nueva, 2 Vols.,Madrid.

HOPPE, J.M. 2004: «Ensayo sobre la escultura de San Pedro de La Nave», en L. Caballero Zoreda (coord.), La iglesia de San Pedro de La Nave (Zamora), 323-345, Zamora.

LÓPEZ MARCOS, M.A., PRESAS VÍAS, M.M., SERRANO HERRERO E. y TORRA PÉREZ, M., 2013: «La fortaleza de Qal'at 'Abd as-Salam. La recuperación de una dignidad perdida (Alcalá de Henares, Madrid)», Arqueología de la Arquitectura, 10: e003, doi: http://dx.doi. org/10.3989/arq.arqt.2013.017

MANZANO MORENO, E., 2006: Conquistadores, emires y califas. Los Omeyas y la formación de al-Andalus, Madrid.

MAQUEDANO CARRASCO, B., 2001: Catálogo de relieves visigodos de Arisgotas (Orgaz, Toledo), Ayuntamiento de Orgaz.

MARQUÉS DE LOZOYA, 1940: «Pinturas murales descubiertas cerca de Madrid. Un nuevo monumento visigótico», Investigación y Progreso, nº 1-2, 13-16.

MARTÍN VISO, I., 2008: "Tremisses y potentes en el nordeste de Lusitania (siglos VI-VII)», Mélanges de la Casa de Velázquez 38/1, 175-200. http://mcv.revues.org/1017

MARTÍN VISO, I., 2011: «Circuits of power in a fragmented space: gold coinage in the Meseta del Duero (sixthseventh centuries)», en J. Escalona y A. Reynolds (eds.), Scale and scale change in the Early Middle Ages. Exploring landscape, local society and the world beyond, The Medieval Countryside 6, 215-252, Turnhout.

MORENO MARTÍN, F. J., 2008: «El yacimiento de Los Hitos en Arisgotas (Orgaz, Toledo). Reflexiones en torno a Cómo «se construye» un monasterio visigodo», Anales de Historia del Arte, 18, 13 - 44.

OCAÑA PRADOS, J., 1908 (reed. 2008): «Santuarios que hubo en la Antigüedad», en Apuntes para la historia de la Villa de Móstoles, 23-24, Móstoles.

PÉREZ VICENTE, D., 1990: «Excavaciones arqueológicas en Calatalifa», en Madrid del siglo IX al XI, 141-144, Madrid.

QUIRÓS CASTILLO, J.A., 2011: «Las iglesias altomedievales en el País Vasco. Del monumento al paisaje», Studia Historica, Historia Medieval, 29, 175-205.

QUIRÓS CASTILLO, J.A. y FERNÁNDEZ MIER, M., 2012: «Para una historia social de la arquitectura monumental altomedieval asturiana», en L. Caballero Zoreda, P. Mateos Cruz y C. García de Castro Valdés (eds.), Asturias entre visigodos y mozárabes (Visigodos y Omeyas VI, Madrid 2010), 27-53, Madrid.

RETUERCE VELASCO, M., 1984: «La cerámica islámica de Calatalifa. Apuntes sobre los grupos cerámicos de la Marca Media», Boletín del Museo Arqueológico Nacional, Tomo II, $\mathrm{n}^{\mathrm{o}}$ 1, 117-136. 
RETUERCE VELASCO, M., 2004: «Testimonios materiales del Madrid andalusí», en A. Turina Gómez, S. Quero Castro y A. Pérez Navarro (coords.), Testimonios del Madrid medieval. El Madrid musulmán, 81-115, Madrid.

RIVERA GARRETAS, M.M., 1995: La encomienda, el priorato y la villa de Uclés en la Edad Media (11741310): formación de un señorio de la Orden de Santiago, Anuario de Estudios Medievales 15, Barcelona.

RODRÍGUEZ MORALES, J., 2005: Informe sobre el patrimonio arqueológico de Móstoles, Informe inédito, entregado al Servicio de Protección del Patrimonio Arqueológico, Paleontológico y Etnográfico de la Dirección General de Patrimonio Histórico de la Consejería de Cultura y Deportes de la CAM el 22 de diciembre de 2005, Madrid.

RODRÍGUEZ MORALES, J., 2007: «Calatalifa, el Viso de Calatalifa y la repoblación segoviana», Anales del Instituto de Estudios Históricos del Sur de Madrid 'Jiménez de Gregorio', 7, 295-325.

RODRÍGUEZ MORALES, J., 2011: «Excavaciones arqueológicas en Móstoles», en Segunda jornada del Instituto de Estudios Históricos del Sur de Madrid 'Jiménez de Gregorio'en Móstoles, 151-167, Madrid.

RODRÍGUEZ MORALES, J. y GARCÍA ROMERO, A., 2002: «Diez argumentos para ubicar Titulcia en Móstoles», Anales del Instituto de Estudios Históricos del Sur de Madrid 'Jiménez de Gregorio', 3, 51-81.

SÁNCHEZ PARDO, J.C., 2012: «Los contextos de fundación de las iglesias tardoantiguas en Galicia (ss. V-VIII): substratos arqueológicos, distribución y significados», Antiquité Tardive, 20, 255-273.

SÁNCHEZ ZUFIAURRE, L., 2007: Técnicas constructivas medievales. Nuevos documentos arqueológicos para el estudio de la Alta Edad Media en Álava, Colección de Patrimonio Cultural Vasco/EKOB 3, Vitoria-Gasteiz.

SASTRE DE DIEGO, I., 2012: Los primeros edificios cristianos de Extremadura. Sus espacios y elementos litúrgicos. Caelum in terra, Ataecina 5. Mérida.

SCHLUNK, H., 1947: «Arte Visigodo, Arte Asturiano», Ars Hispaniae II, 227-416, Madrid.

UTRERO AGUDO, M.A., 2006: Iglesias tardoantiguas y altomedievales en la Península Ibérica. Análisis arqueológico y sistemas de abovedamiento, Anejos de Archivo Español de Arqueología, XL, Madrid.

UTRERO AGUDO, M.A., 2010: «Late Antique and Early Medieval Hispanic churches and the archaeology of architecture: revisions and reinterpretation of constructions, chronologies and contexts», Medieval Archaeology, 54, 1-33.
VIGIL-ESCALERA GUIRADO, A., 2003: «Cerámicas tardorromanas y altomedievales de Madrid», en L. Caballero, P. Mateos y M. Retuerce (eds.), Cerámicas tardorromanas y altomedievales en la Península Ibérica. Ruptura y continuidad (II Simposio de Arqueología. Mérida, 2001), Anejos de Archivo Español de Arqueología XXVIII, 371-387, Madrid.

VIGIL-ESCALERA GUIRADO, A., 2007: «Granjas y aldeas altomedievales al Norte de Toledo (450-800 d.C.)», Archivo Español de Arqueología, 80, 239-284.

VIGIL-ESCALERA GUIRADO, A., 2009: «Sepulturas, huertos y radiocarbono (siglos VIII-XIII d.C.). El proceso de islamización en el medio rural del centro peninsular y otras cuestiones», Studia Historica, Historia Medieval, 27, 97-118

VIGIL-ESCALERA GUIRADO, A., 2011: «Formas de poblamiento rural en torno al 711: documentación arqueológica del centro peninsular», Zona Arqueológica, 15.2, 188-201.

VIGIL-ESCALERA GUIRADO, A., 2013a: «Comunidad política aldeana y exclusión. Una revisión de las formas de inhumación altomedievales (ss. V-VIII d.C.)», Reti Medievali, 14/1, disponible en http://www.rmojs.unina. it/index.php/rm/article/view/386

VIGIL-ESCALERA GUIRADO, A., 2013b, «El registro arqueológico del campesinado del interior peninsular en época altomedieval», en J.A. Quirós Castillo (ed.), El poblamiento rural de época visigoda en Hispania. Arqueología del campesinado en el interior peninsular, Documentos de Arqueología Medieval 6, 65-259, Bilbao.

VIGIL-ESCALERA GUIRADO, A., e.p.: «Meeting places, markets and ecclesiae in the countryside between Madrid and Toledo, central Spain (ca. AD 500-900)», en J. Escalona, S. Brookes y O. Vesteinson (eds.), Neighboring localities, Turnhout.

VIGIL-ESCALERA GUIRADO, A. y QUIRÓS CASTILLO J.A., 2013: «Un ensayo de interpretación del registro arqueológico», en J.A. Quirós Castillo (ed.), El poblamiento rural de época visigoda en Hispania. Arqueología del campesinado en el interior peninsular, Documentos de Arqueología Medieval 6, 357-399, Bilbao.

VILLAR GARCÍA, L.M., 1990, Documentación medieval de la Catedral de Segovia (115-1300), Salamanca.

VILORIA ROSADO, J.L., 1955: «Yacimientos arqueológicos de Madrid y alrededores», Archivo Español de Arqueología, XVIII, 91, 135-142.

ZADORA-RIO, E., 2005, «Territoires paroissiaux et construction de l'espace vernaculaire», Médiévales [en ligne], $49 \mathrm{http}: / /$ medievales.revues.org/1306 